\title{
Compare Study of Corporate Innovation Capacity and its Evaluation Indices
}

\author{
Tonghua Mou \\ School of Economics \\ Shenzhen Polytechnic \\ Shenzhen GuangDong, P.R.China \\ e-mail: thmu@szpt.edu.cn
}

\author{
Fang Du \\ School of Management \\ Shenzhen Polytechnic \\ Shenzhen GuangDong, P.R.China \\ e-mail: dufang_63@hotmail.com
}

\begin{abstract}
This article is aimed to systemically summarize worldwide scholars' research achievements of the core issues such as connotation of corporate technical innovation, technical innovation capability, evaluation index system, evaluation methods, etc., and put forward the methods and paths for further studies on corporate technical innovation; meanwhile, as to the concept of corporate innovation, connotation of technical innovation, relevant elements of technical innovation capability as well as the evaluation indexes and methods of innovative achievements, the article has made in-depth discussions and comparative studies based on varied perspectives; besides, according to this article, firstly, it is necessary to build differentiated evaluation index systems and evaluation methods, as to the evaluation of corporate technical innovation ways, by integrating various influential factors like corporate economic environment, manufacturing environment, policy environment and corporate type; secondly, it is necessary to systemically conduct comparative studies on the technical innovations of Chinese-Foreign enterprises in order to find out common points, innovative rules and implement approaches to provide Chinese-Foreign enterprises with valuable experiences for their technical innovation; the unique feature of this article is reflected in that it integrates worldwide scholars' different study perspectives, systematically analyzes the core factors of corporate technical innovation, summarizes the rule of similarities, and provides enterprises with new perspectives and thinking modes for technical innovation.
\end{abstract}

Keywords-corporate innovation; innocation capacity ; evaluating indicator

\section{OVERVIEW OF THE CORPORATE INNOVATION CONCEPT AND ITS MEANING}

Up to the present time, there has been no a uniform definition of corporate innovation in the academia. J.A. Schumpeter is one of the economists who studies corporate innovation. He believes that Schumpeter's innovation concept covers five areas: the introduction of a new good $\rightarrow$ the introduction of a new method of production $\rightarrow$ a new market source of supply $\rightarrow$ establishment and monopoly of the new supply(raw materials and semi-finished goods $\rightarrow$ establishment of new industrial organisations and commercial pattern. The innocation concept defined by Schumpeter is fairly extensive, covering the production, technical and managerial processes and incorporating extensive contents such as technical innovation, product innovation, process innovation, market innovation and organizational system innovation[1].

Following Schrumpeter, many scholars define innovation from their own research perspectives. Van de Ven(1986)defines innovation as the development and implementation of a new concept by traders under the

norm of a system. The definition emphases four elements: new concept, trader, transaction and system environement [2].Roberts(1988)maintains that corporate innovation includes two parts: (1) the emerging of human thought or invention; (2)commercial transformation of the invention or other usages. Therefore, innovation includes various stages from the inception of invention to commercialization. So corporate innovation management should incorporate the effective application of the labor resources and capital to the following: (1) the creation of knowledge; (2) technical progress aiming to improve the product, production process and service; (3) work formation upon the improvement; (4) production, circulation and utilization[2].

Ettlie, Bridges and O' Keefe (1984)define innovation as breakthrough innovation and progressive innovation. Breakthrough innovation is radical change, which represents the technically revolutionary change whereas the progressive innovation is mere adjustment to and local modification of the existing technology[3]. Cardinal(2001)defines the breakthrough and progressive innovations from the perspective of knowledge. He maintains that breakthrough innovation is tremendous technical progress based on the discovery of knowledge, which needs to bear huge technical risks and consume a great amount of time and cost. On the other hand, progressive innovation is based on the framework of the existing knowledge, a sligh improvement of the existing technology[4].

In the concept of Innovation, what is highlighted are the pure technical invention or creation, but it is not corporate innovation. It may be that corporate innovation is based on a certain technical invention and creation, but corporate innovation is not necessarily so. Schrumpeter believes that so long as an invention is not utilized in reality, it does not play an economic role. Any improvement of it to make it more effective is a task different from its invention and this task requires different capacity (J. A. Schumpeter, 1934).

Two points can be seen from the different definitons of corporate innovation mentioned above. The first is that 
different definitions and explanations are given by different scholars from different perspectives; the commercialization of innovation is emphasized. The second point is that although different scholars classify the innovation from different perspectives, they all regard innovation as several different processes. It is considered a combination of scientific concepts, technical application and commercialization. The connotation of corporate innovation lies in three aspects of technical innovation, system innovation and management innovation, of which the technical innovation is most dealth with.

\section{OVERVIEW OF THE CORPORATE TECHNICAL INNOVATION}

Technical innovation is one of the critical areas in the research on corporate innovation. There is a gradual evolution of the understanding of the technical innovation in the academia. There are dozens of different concepts emerging. In the early stage, the academia put forward various definitions of technical innovation based their own understanding of the concept given by Schumpeter and gradual extenions are made. Enos defines technical innovation from the perspective of behavior integration, maintaining that technical innovation is the result of synthesis of several acts, such as capital input guarantee, establishment of organization, making plans, labor recruitment and market exploration[5]. Mansfield maintains that technical innovation is the various steps of progressively introducing a new product or new process, including the technology, the design, the production, the finance, the management and the market[6].

In PRC, a comparatively sound system of technical innovation theory has been formed in the research on technical innovation. According to $\mathrm{Xu}$ Qingrui, technical innovation refers to all the activities ranging from the inception of a new idea to the successful commercialization of the idea. It includes a series of the scientific, technical and management activies ranging the entire process from the scientific discovery, invention, their introduction into the market, the commercialization and the extention of the application[7]. According to Guan Shixu, technical innovation does not refer to the innovation of the technology proper, but rather the restructuring of the production elements resulting from the introduction of the technical achievement or the transfer of the production function[8]. Professor Fu Jiaji defines technical innovation as "series of the comprehensive processes in the aspects of science, organization, commercialization and financing in which the enterpreneur grasps the potential market opportunity of making profit to obtain the target of commercial gains by restructuring the production conditions and elements, establishing effective and powerful, highly efficient and cost-effective production and management systems so as to launch new products, new processes, to explore new markets, to obtain new raw materials or semi-finished products supplies or establishing new organizations[9]. Jia Weiwen et al.maintain that technical innovation is the sum of a series of activities from the inception of a new product or process including the research, development, engineering, commercialized production as well as the market application[10].

Dr. Liu Xielin deal into the various aspects of technical innovation economics in a systematic fashion in hie treatise Technical Innovation Economics in 1992. He does not only reveal the technical innovation process and mechanism and technical innovation and market organization, enterprices, evelutionary process and the relationship between the economic growth but also analyzes various issues such as innovation policy, tehcnical innovation economics and dealt into the technical innovation incentive[11].

The above definitions define the concept of innovation from the perspectives of the processes and the combinations of elements, namely, in terms of the processes, what processes technical innovation includes and what the beginning and the finishing points are. The beginning mainly refers to the inception of the innovative idea while the finishing point is referred by early scholars to as the successful development of new technology or new product, and later to as realization of the market value by the new product, the improvement of the corporate competitiveness of the product etc. In terms of the combination of elements, innovation is defined from the combination of the innovative resources that the innovative body possesses. The innovative resources include the corporate labor, capital, system and management etc. But there has been no unanimous consensus among the academia concerning the concept of technical innovation. The debate centers around three aspects. The first one is the definition of the technical scope utilized in the technical innovation, namely, whih innovative activities re technical, which are not. The second one is whether the technical innovation has no restriction on the strength of the technical change and to what degree it has restriction. The third point is what the benchmark of technical innovation is.

\section{RESEARCH ON TECHNICAL INNOVATION CAPACITY AND ITS EVALUATION INDICES}

The research on technical innovation has been going on for more than a half century. However, it was not until 1980s that technical innovation capacity was put forward and studied. From the research done home and abroad, it can be seen that different scholars define corporate innovation capacity from different perspectives to analyze the components of technical innovation capacity. For example, Burgel maintains that corporate innovation capacity is a series of comprehensive features to support the corporate new strategy, including the resources available and the allocation, comprehensibility of the industry development, the comprehensibility of the technical development, the strategic capacity, the structure and cultural conditions[12].Larry E. Westphal believes that innovation capacity is a synthesis of the organizational capacity, the adatability, technical innovation capaity and acquiring information. Seven Muller thinks that innovation capacity is the synthesis of the product development capacity, the production skill capacity improvement, the storage capacity, the production capacity and the organization capacity[12]. D. L. Barton asserts that the core of the corporate innovation 
capacity is the people with the professional knowledge, the technical system capacity, the management system capacity the outlook of the enterprise[12]. Table 1 exhibits the composition of the technical innovation capatity in different perspectives.

All in all, the corporate technical innovation capacity is a comprehensive capacity system composed of several main elements. It is the sum of the internal conditions under which the enterprise can implement and complete the technical innovation as the main part of the technical innovation. Due to the important role that technical innovation capacity plays in the technical innovation, the technical innovation capacity has become a hot topic of research home and abroad. Despite the differences in scholars' concrete expression of technical innovation capacity, the contents revealed are generally similar. Almost all scholars regard corporate technical innovation capacity as a comprehensive capacity system composed of several main elements and as a sum of several intrinsic conditions for the corporate technical innovation.

TABLE I. COMPOSITION OF THE TECHNICAL INNOVATION CAPATITY IN DIFFERENT PERSPECTIVES

\begin{tabular}{|c|c|c|}
\hline Perspective Of Analysis & Composition Of Technical Innovation Capacity & $\begin{array}{l}\text { Representative } \\
\text { scholars }\end{array}$ \\
\hline \multirow[b]{2}{*}{ Organizational behavior } & Synthesis of organization capacity, adaptability, innovation capacity and information acquisition & Larry \\
\hline & $\begin{array}{l}\text { The technical innovation capacity is considered the combination of a resource available, the } \\
\text { understanding of rivals, the understanding of the environment, the organizational structure and } \\
\text { change, the exploring strategy }\end{array}$ & Bergman \\
\hline $\begin{array}{l}\text { Resources elements of } \\
\text { technical innovation }\end{array}$ & $\begin{array}{l}\text { The technical innovation capacity is broken down into several aspects such as technical } \\
\text { innovation input capacity(including the } R \& D \text { personnel, } R \& D \text { funds, patents), the output capacity } \\
\text { and activity process capacity and internal support of corporate technical innovation social support etc. }\end{array}$ & $\begin{array}{l}\text { Wang Jian, } \\
\text { Wang Haishan }\end{array}$ \\
\hline & $\begin{array}{l}\text { The technical innovation capacity is composed of the skills of the technicians and senior } \\
\text { technicians, the technical system capacity, the management capacity, the outlook etc. }\end{array}$ & Barton \\
\hline & $\begin{array}{l}\text { From the linking perspectives of product innovation capacity and process innovation capacity, } \\
\text { the combined innovation capacity is put forward, namely the product innovation capacity, process } \\
\text { innovation capacity and the integral systematic function thus determined. }\end{array}$ & Wang Weiqiang \\
\hline \multirow{4}{*}{$\begin{array}{l}\text { Technical innovation } \\
\text { process }\end{array}$} & $\begin{array}{l}\text { The technical innovation capacity is broken down into the innovative resources capacity, the } \\
\text { innovative management capacity, the innovative aptitude, the R\&D capacity, the manufacturing } \\
\text { capacity and marketing capacity. }\end{array}$ & \\
\hline & $\begin{array}{l}\text { The } 5 \text { components of the technical innovation: innovative decision capacity, R\&D capacity, } \\
\text { production capacity, marketing capacity and organizational capacity. }\end{array}$ & $\begin{array}{r}\text { Wei } \\
\text { Q }\end{array}$ \\
\hline & $\begin{array}{l}\text { The technical innovation capacity is in fact the overall system capacity of an enterprise with the } \\
\text { product innovation capacity, the production technical innovation capacity and management technical } \\
\text { innovation capacity as the mainstay, namely, the capacity of coordination to realize the economic } \\
\text { profit. Based on the technical innovation process, the main content and the affecting factors, the } \\
\text { technical innovation capacity can be broken down into seven aspects: R\&D capacity, production } \\
\text { capacity, organization management capacity, input capacity, marketing capacity, financing capacity, } \\
\text { output capacity. }\end{array}$ & \\
\hline & $\begin{array}{l}\text { On the basis of profound analysis of the technical innovation operation mechanism, the technical } \\
\text { innovation capacity can be defined as production technical innovation decision capacity, R\&D } \\
\text { capacity, implementation capacity, realization capacity and organization management capacity with } \\
\text { the capacity elements during the entire innovation process broken down and analyzed. }\end{array}$ & Shixu \\
\hline & $\begin{array}{l}\text { The technical innovation capacity is broken down into the capacity of the corporate technical and } \\
\text { market opportunity selection, the technical design and R\&D capacity, sample manufacturing capacity, } \\
\text { pilot project capacity, scale production capacity, sales and market exploring capacity, market } \\
\text { information and feedback and product updating capacity etc. }\end{array}$ & \\
\hline \multicolumn{3}{|c|}{ 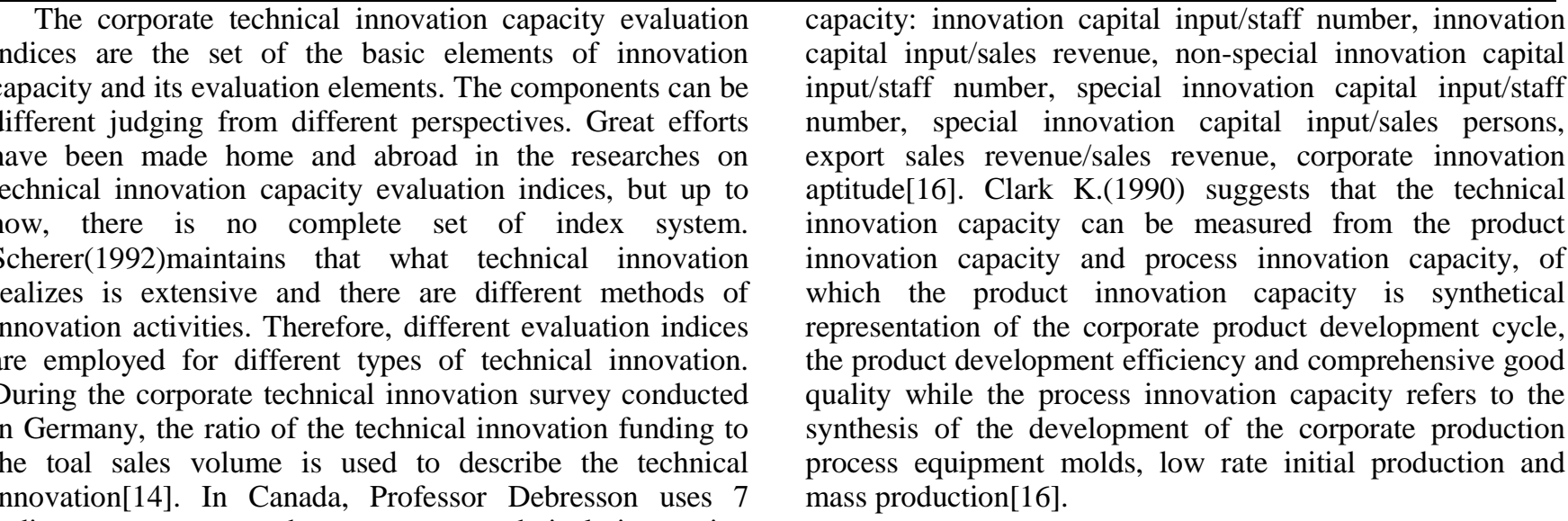 } \\
\hline
\end{tabular}
indices to compare the corporate technical innovation 
In recent years, the Statistics Administration of PRC has

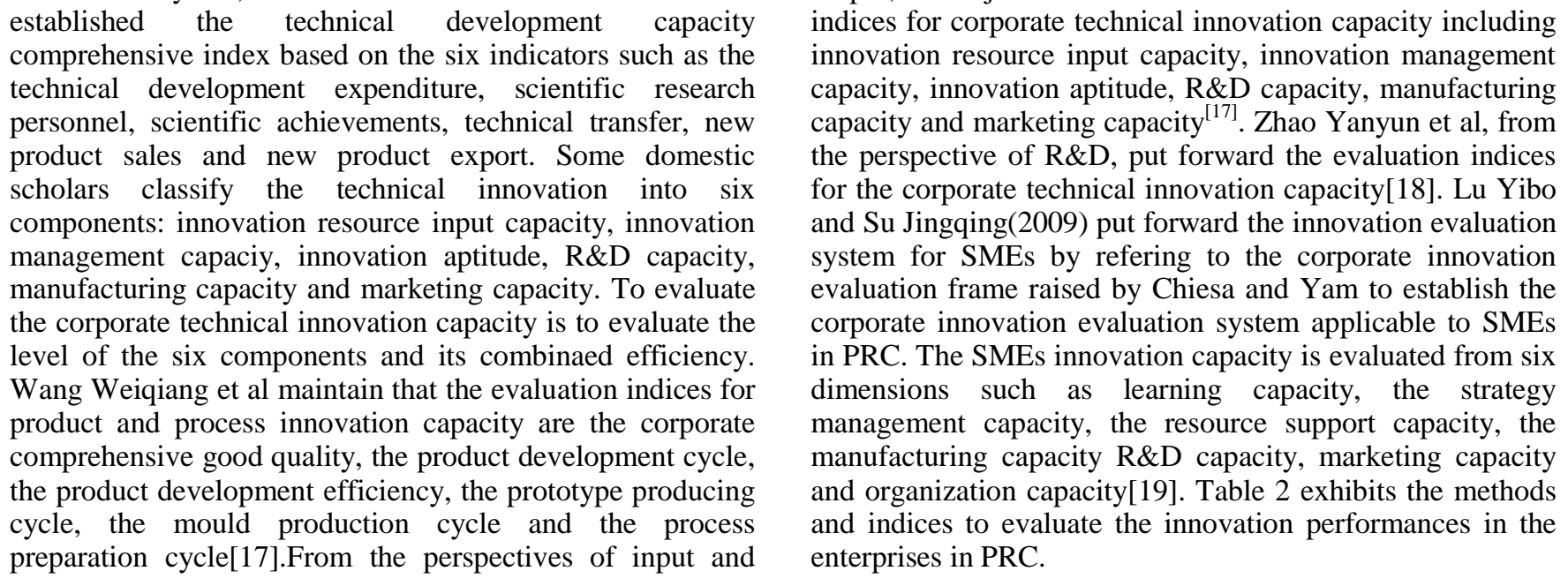

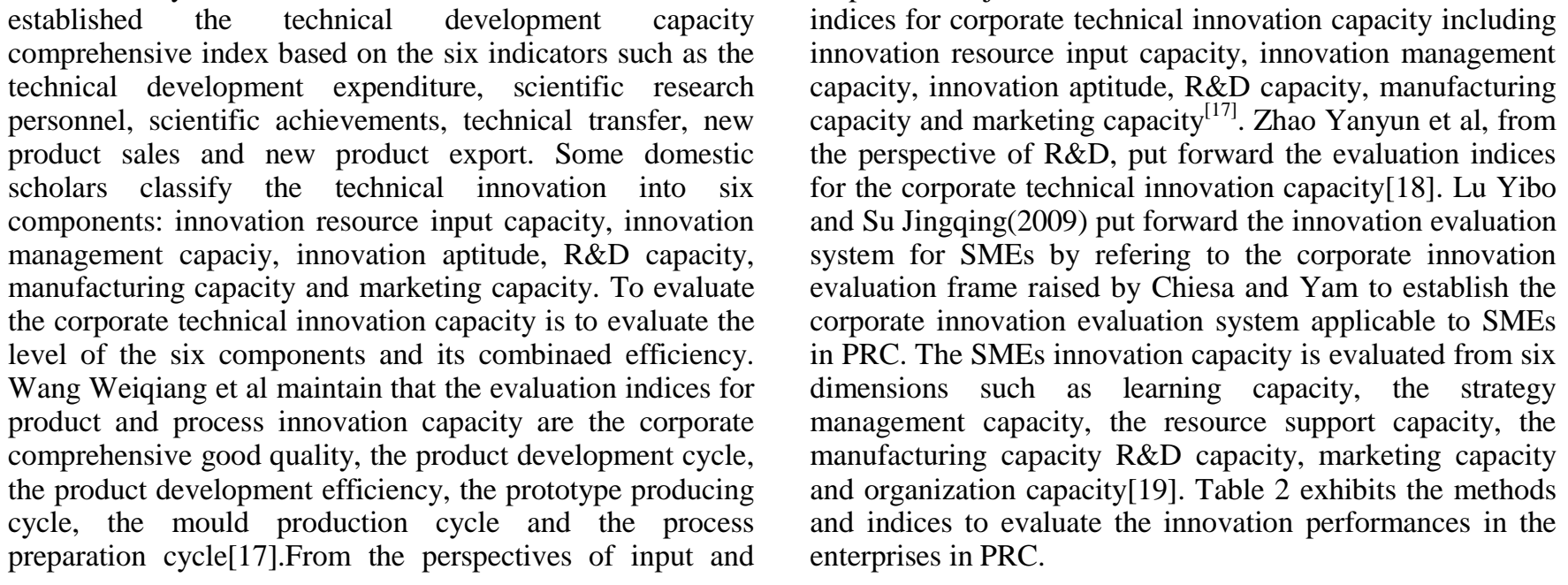

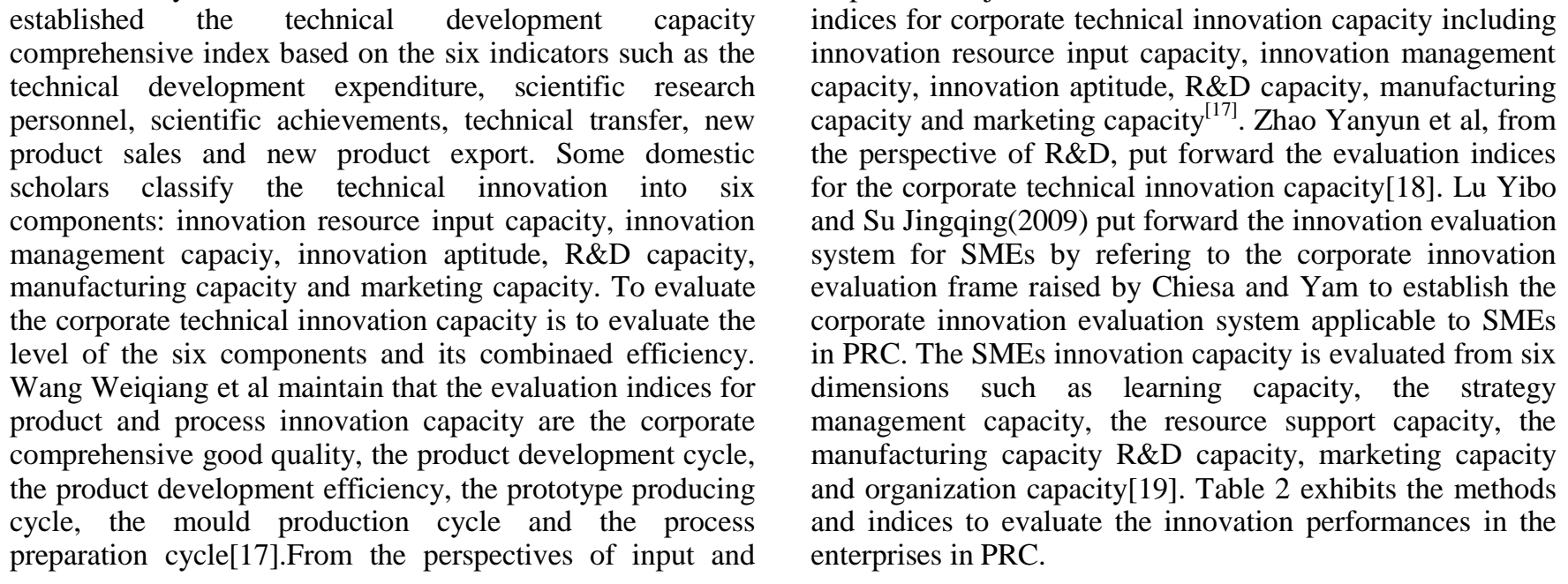

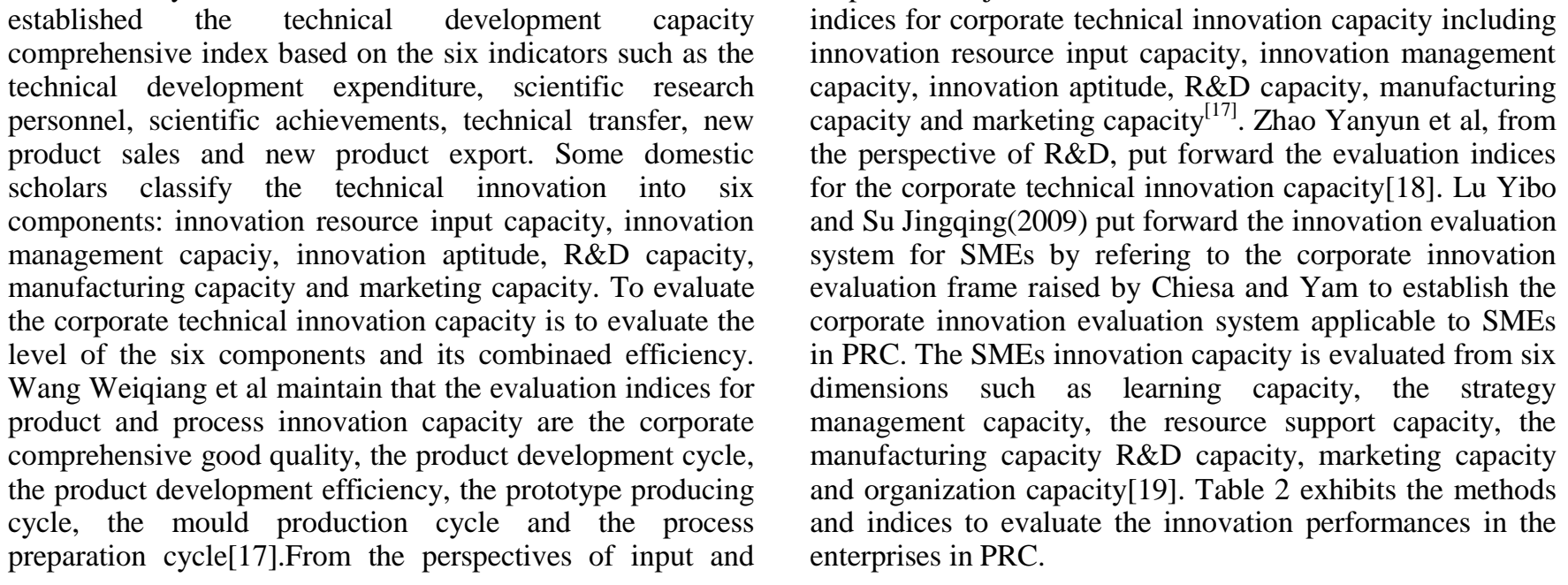

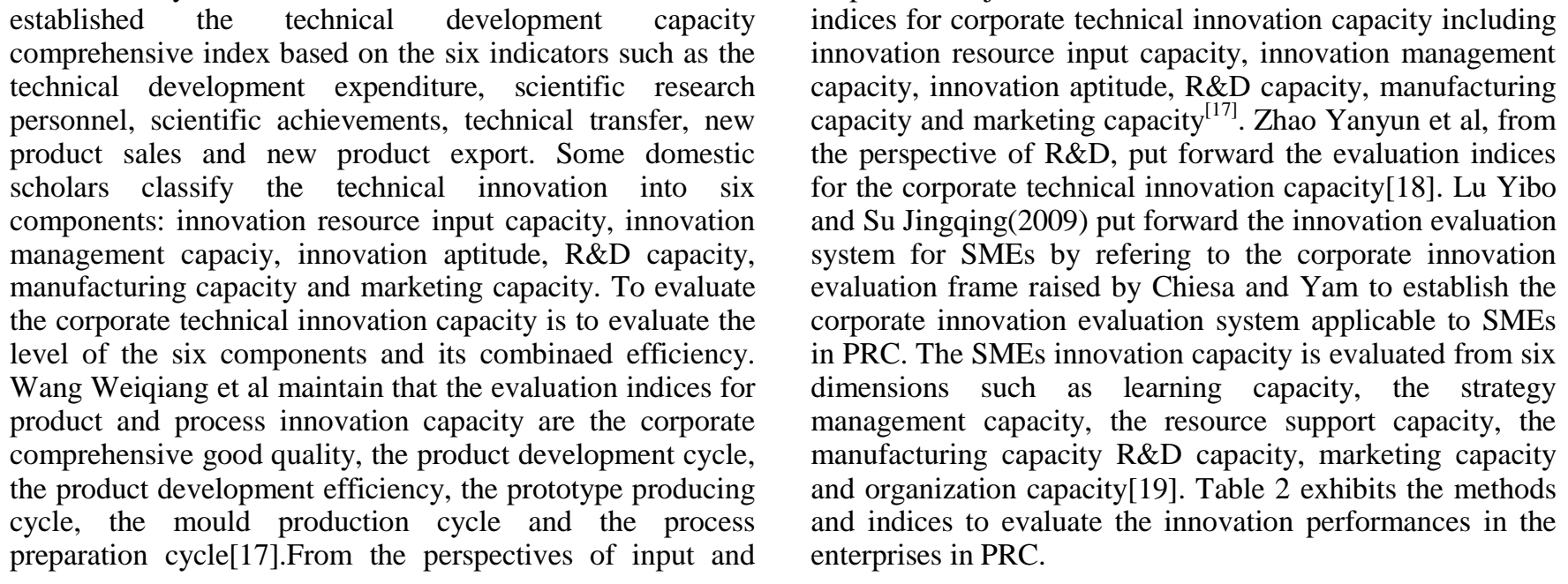

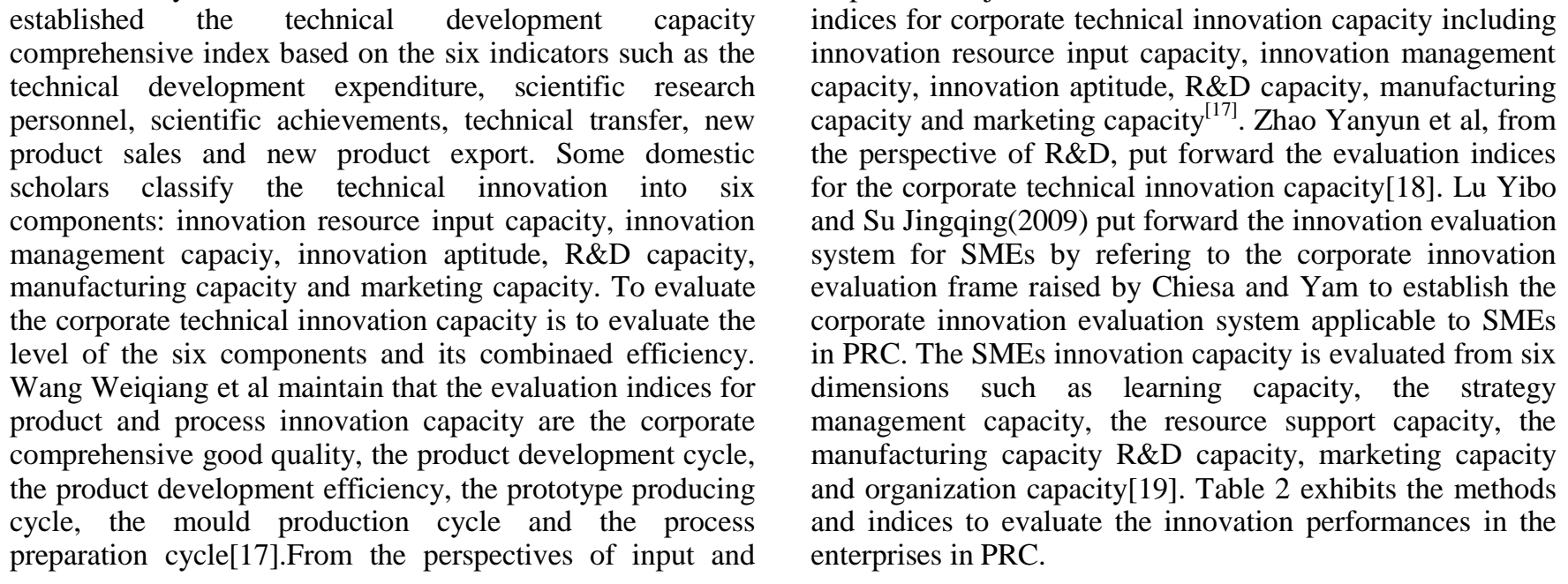

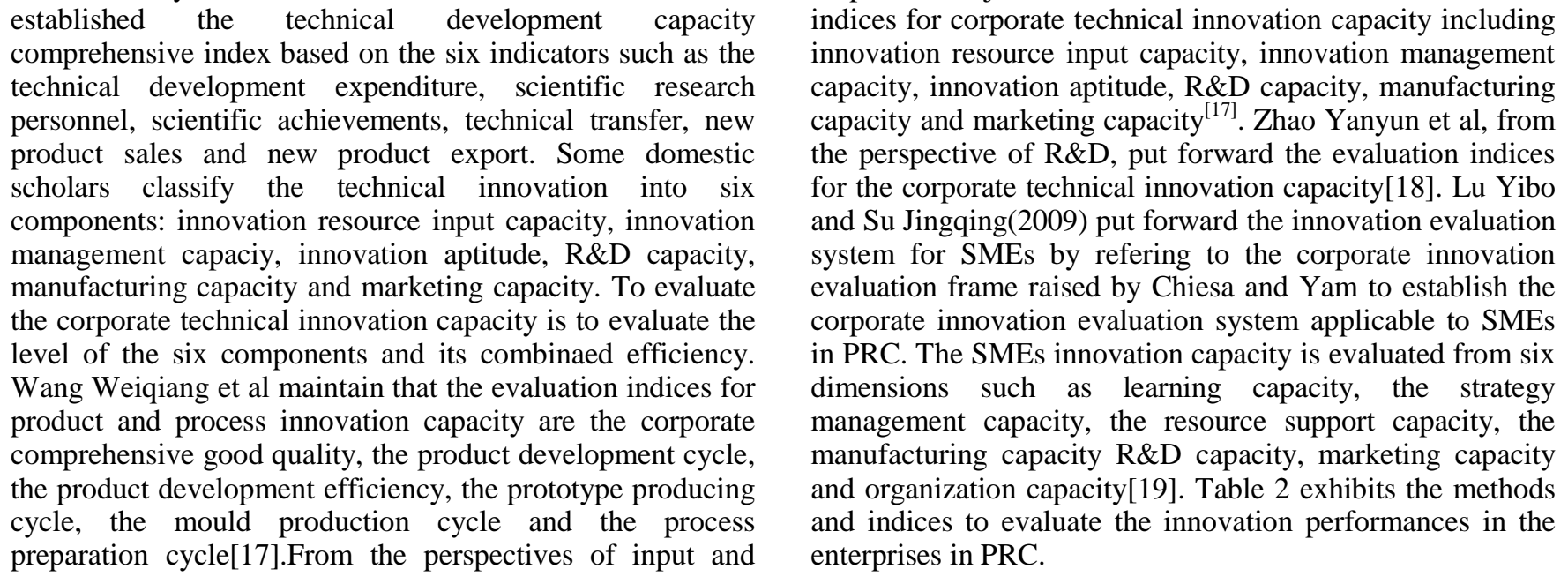

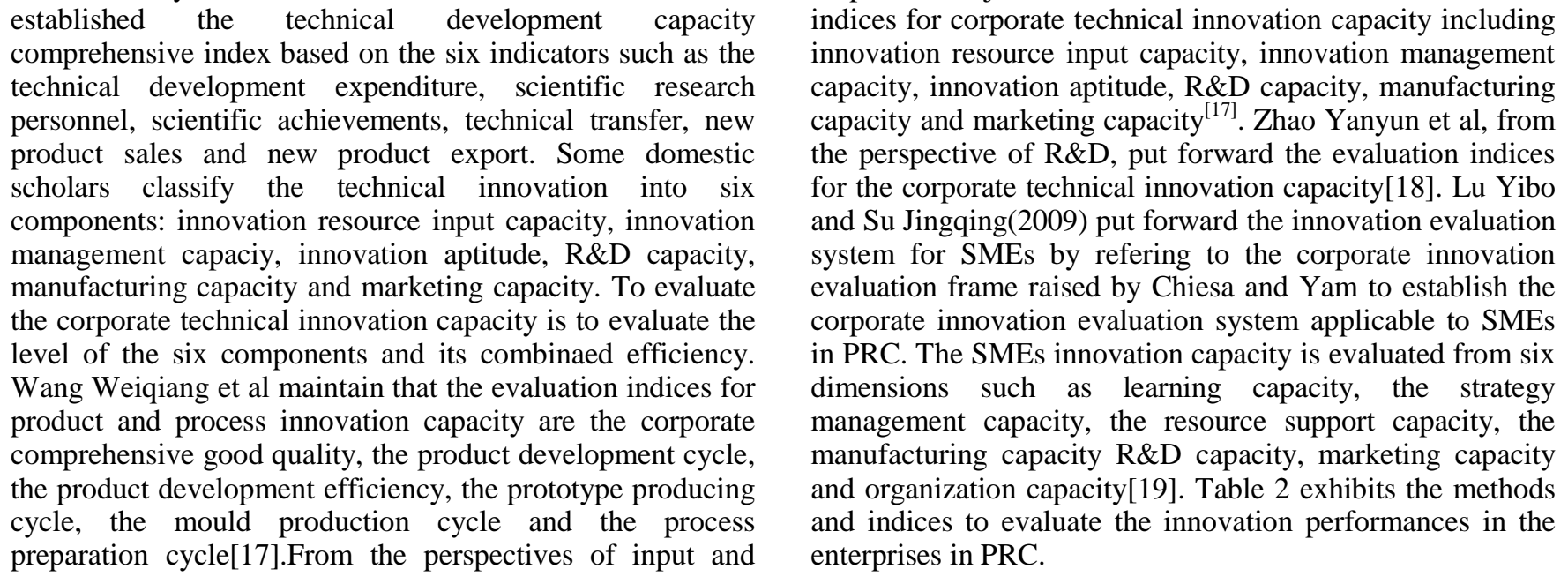

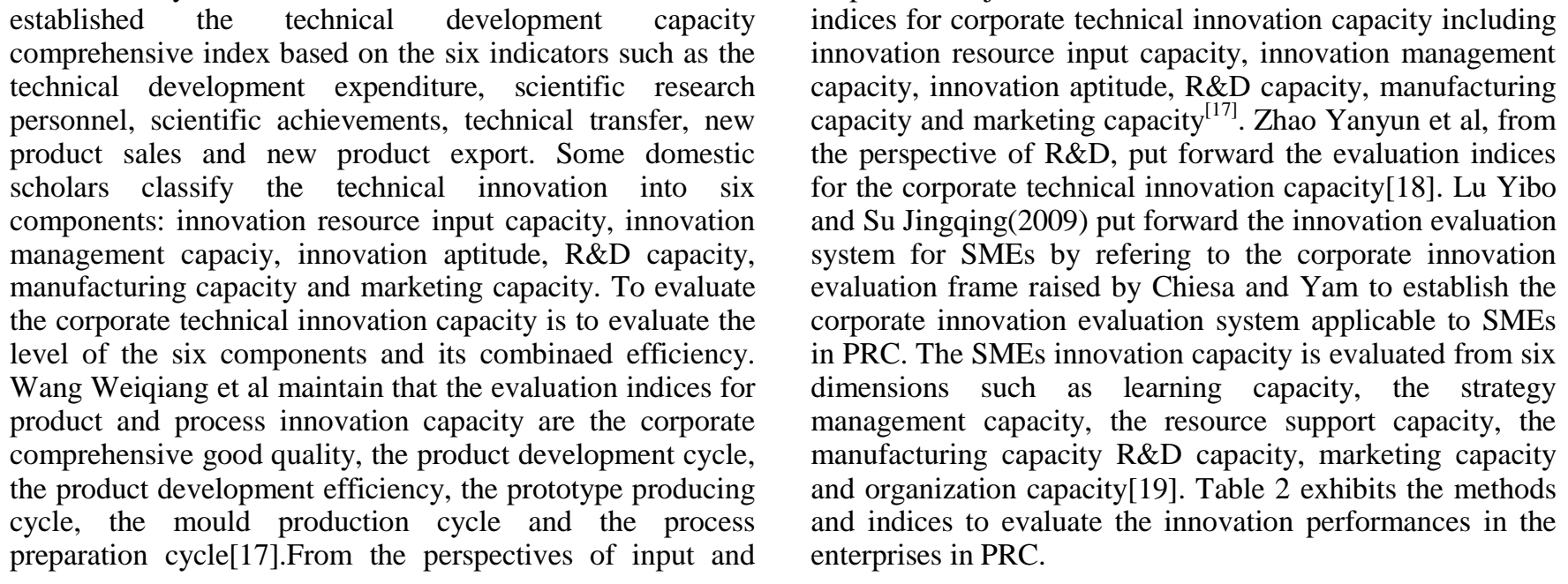

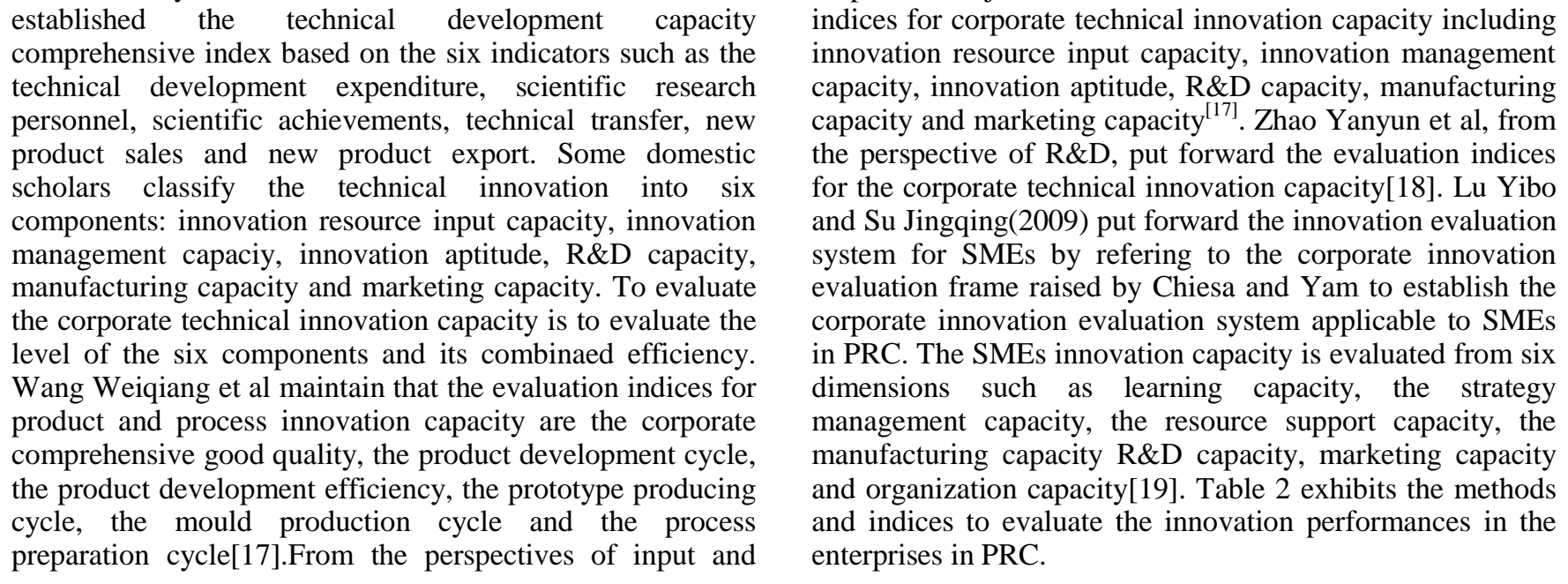

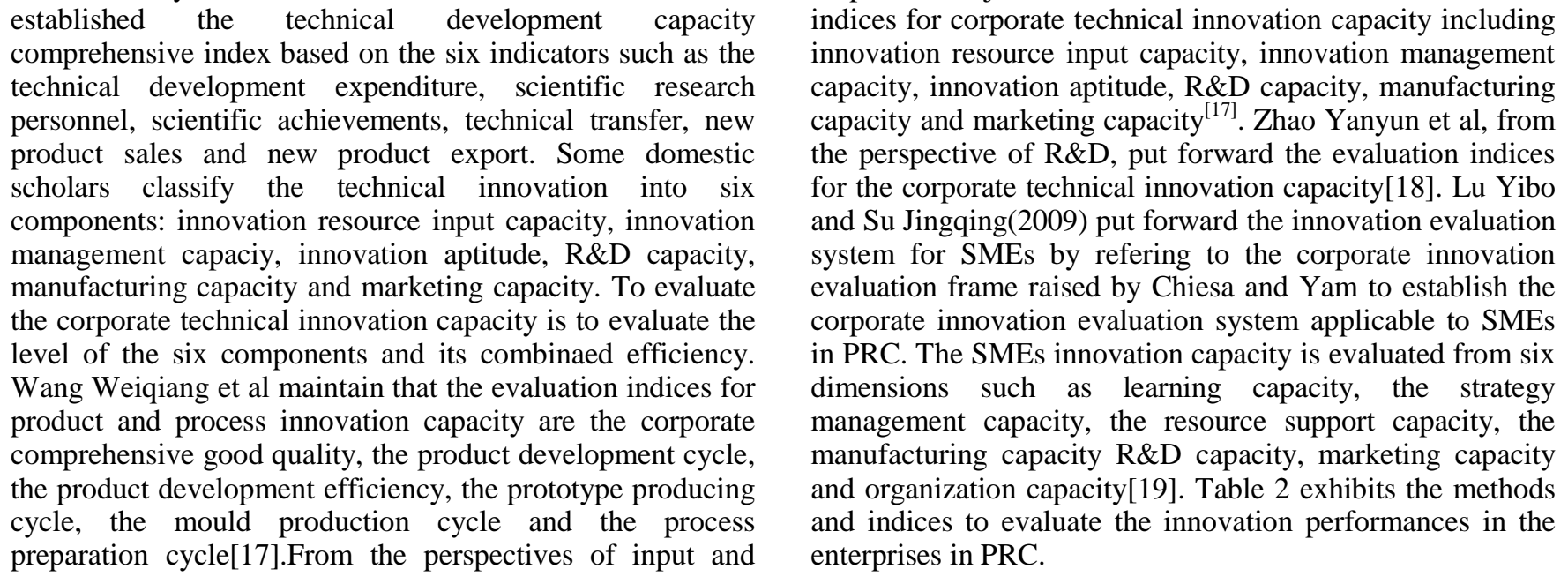

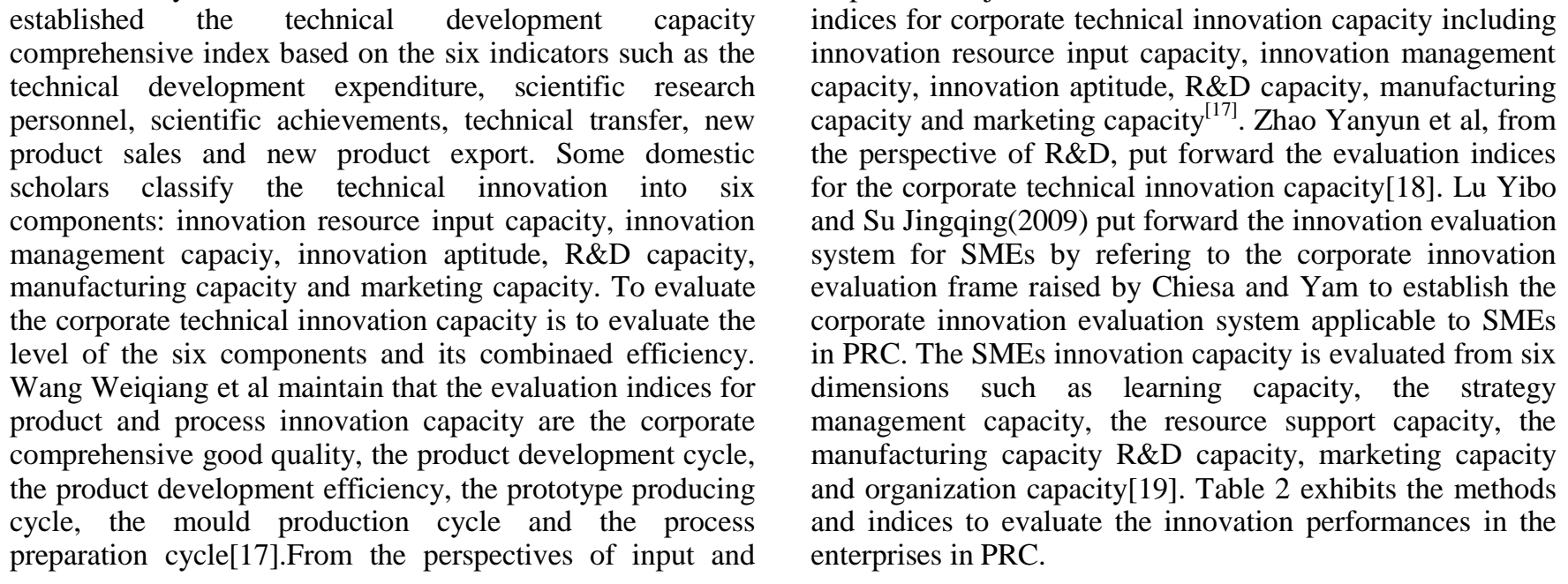

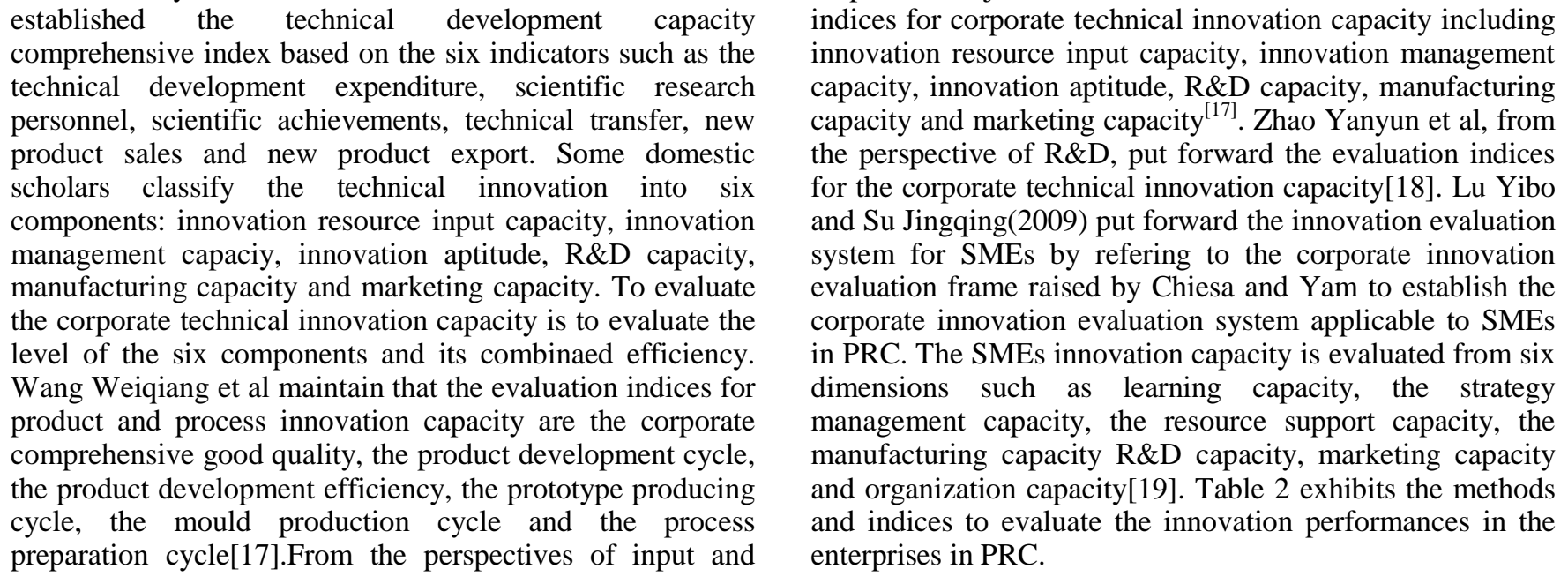

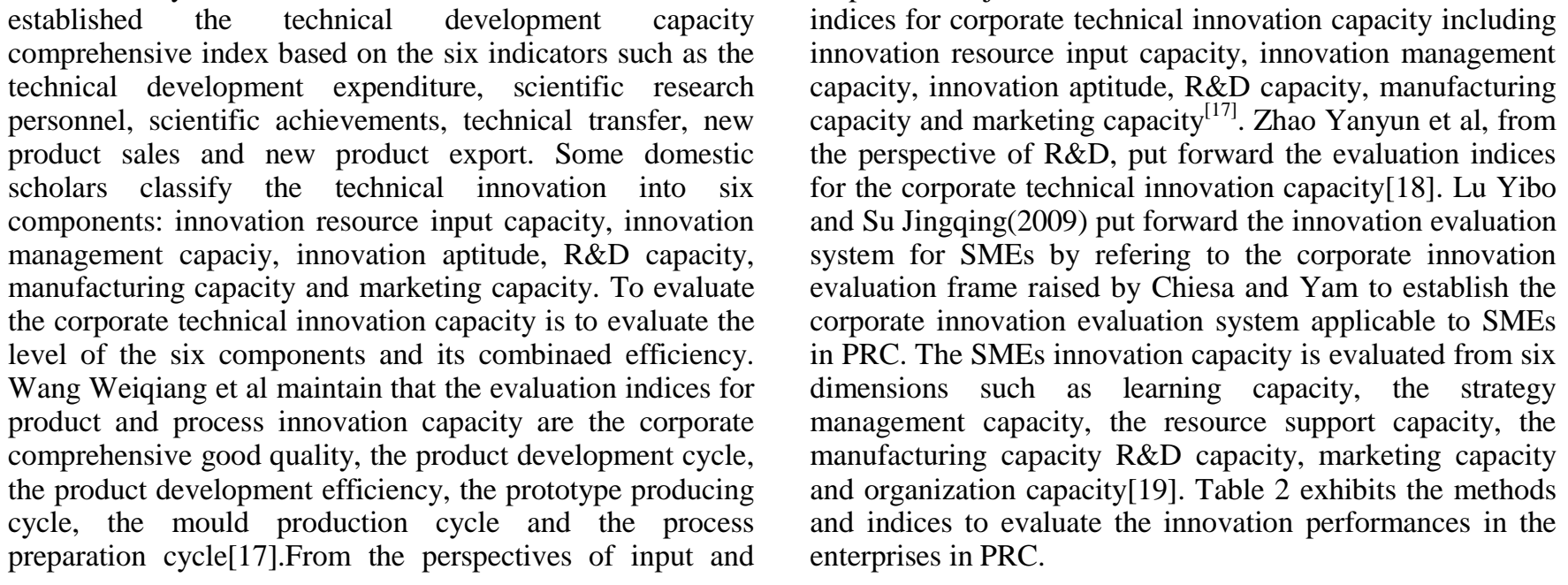

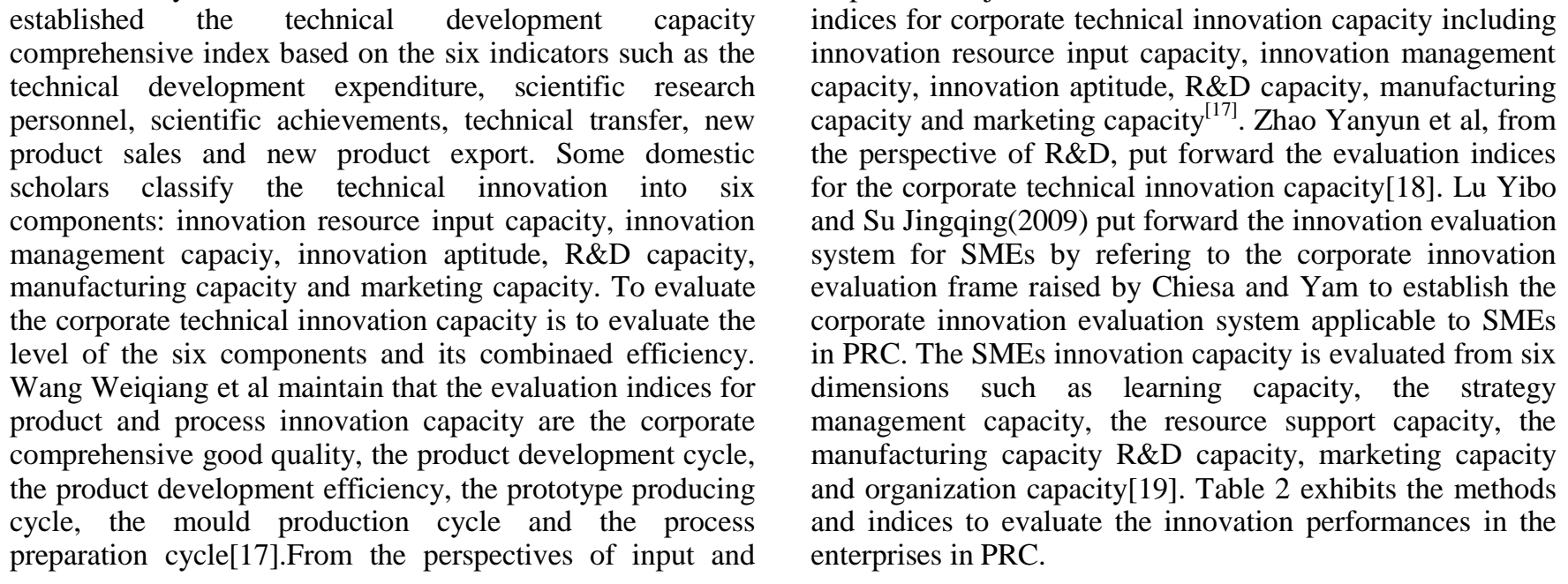

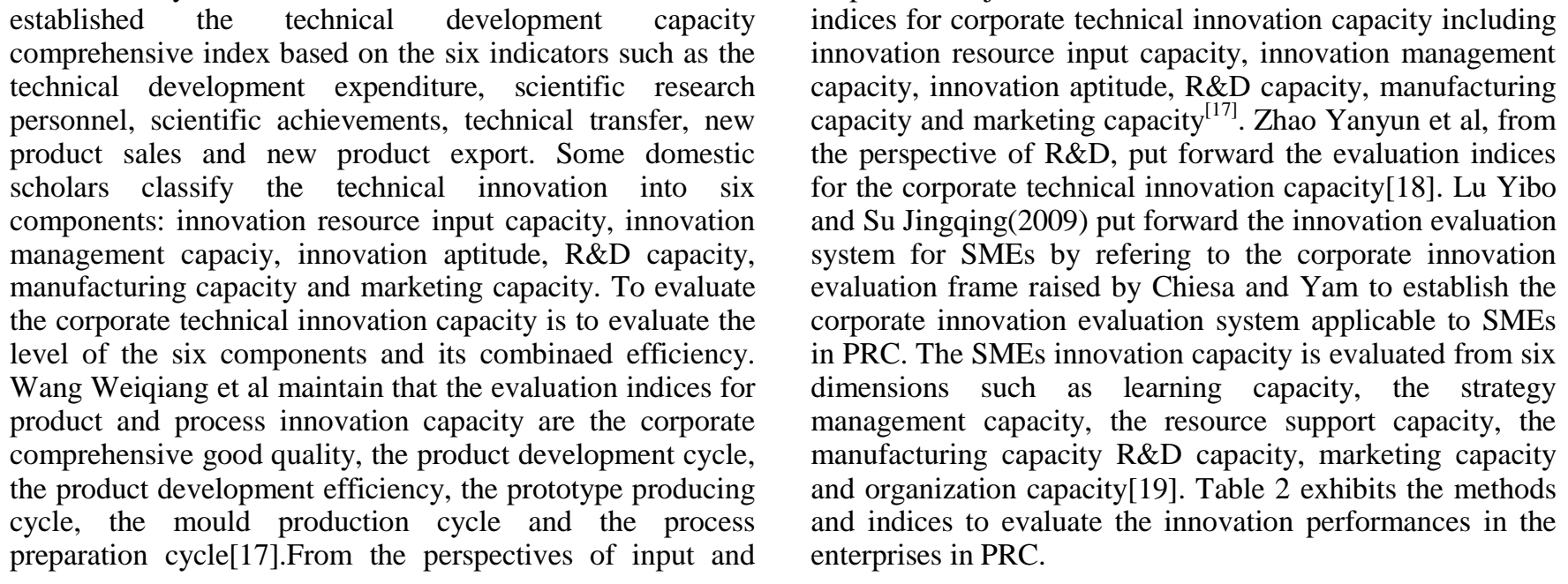

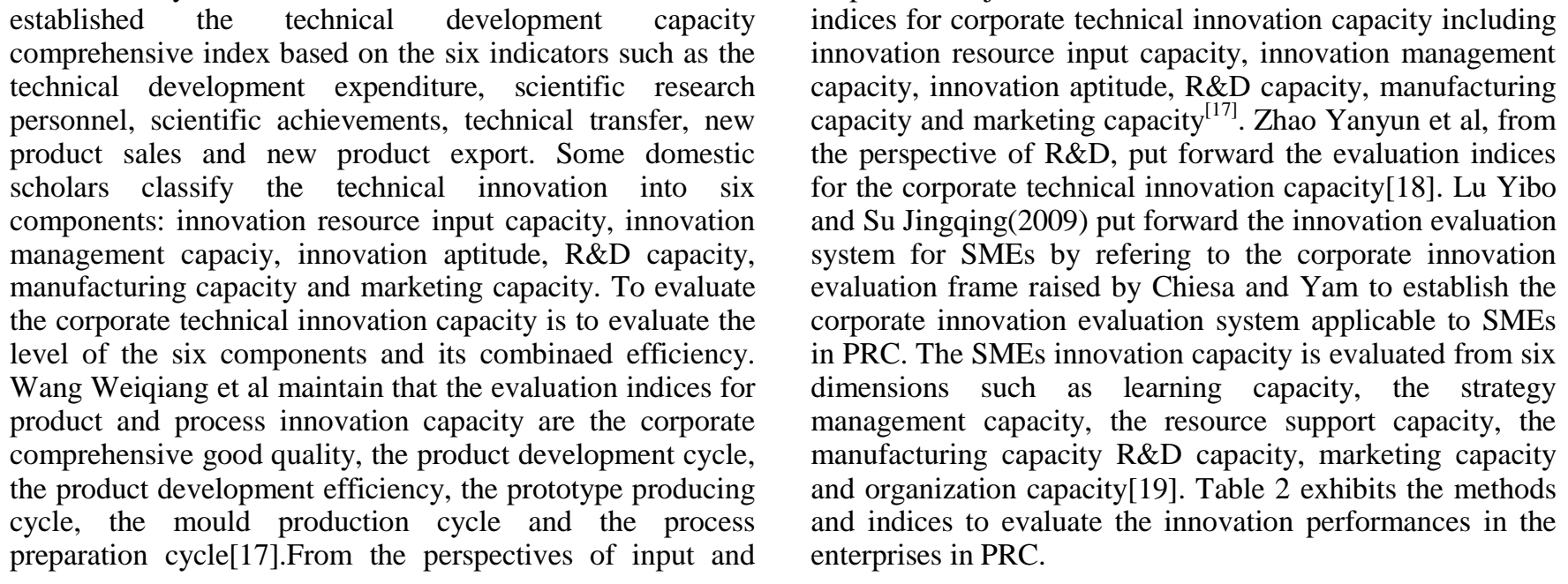

output, Fu Jiaji et al consider six indices as the evaluation

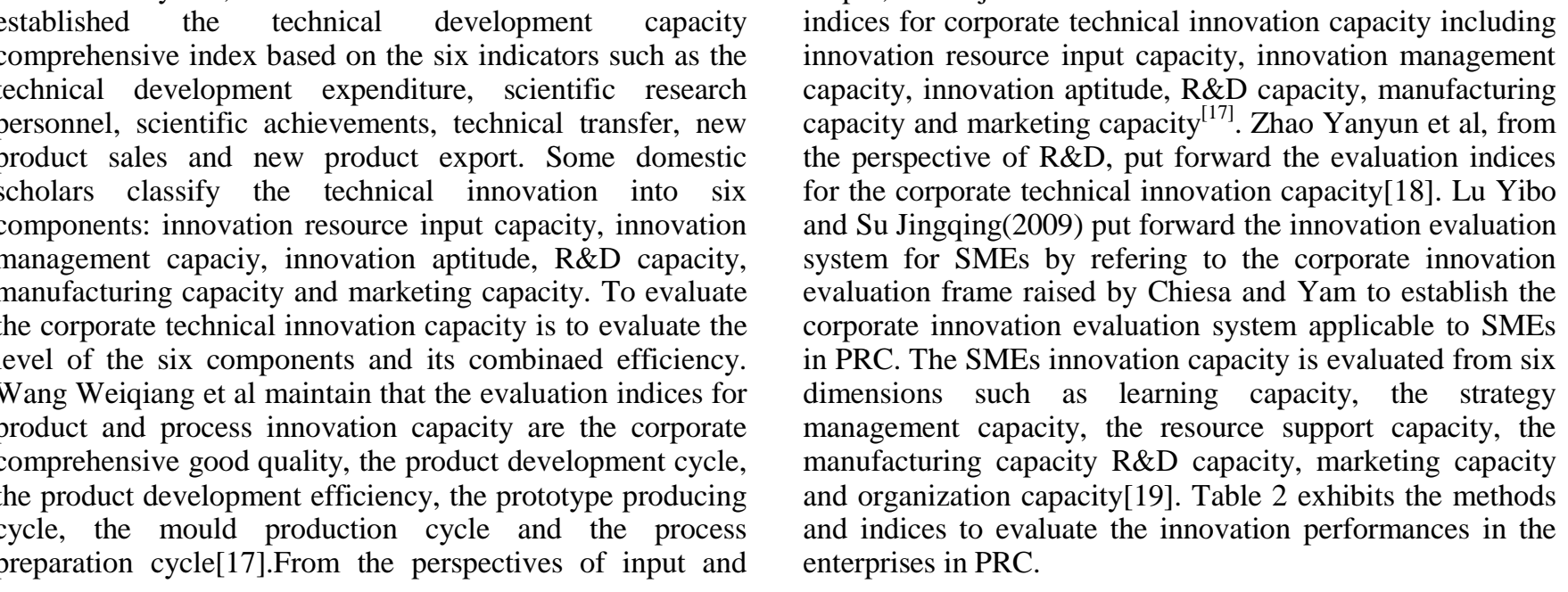

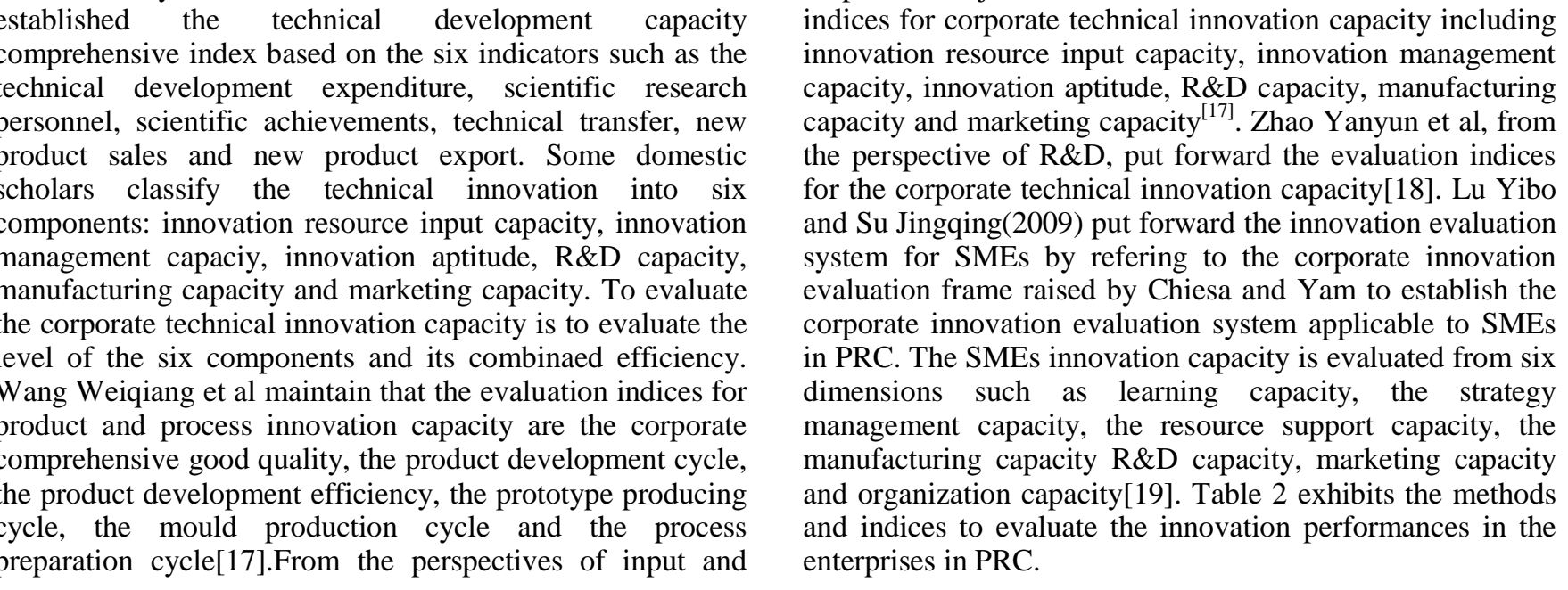

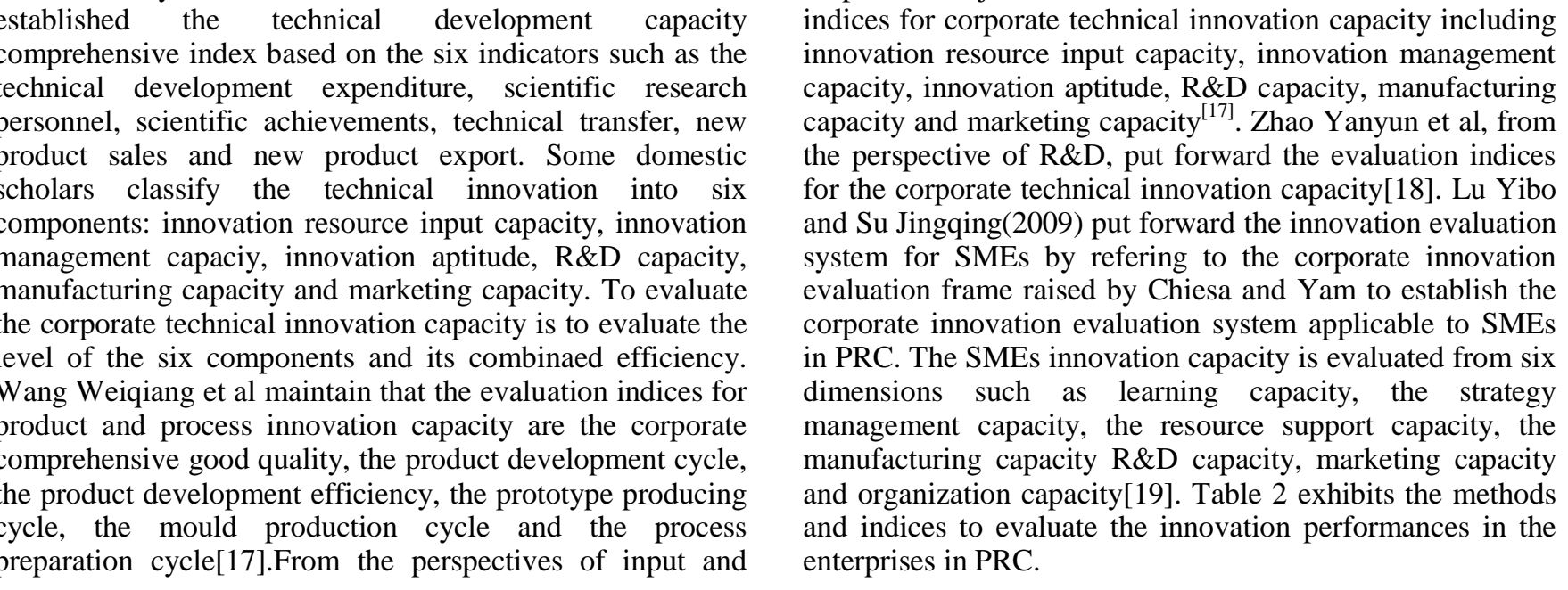

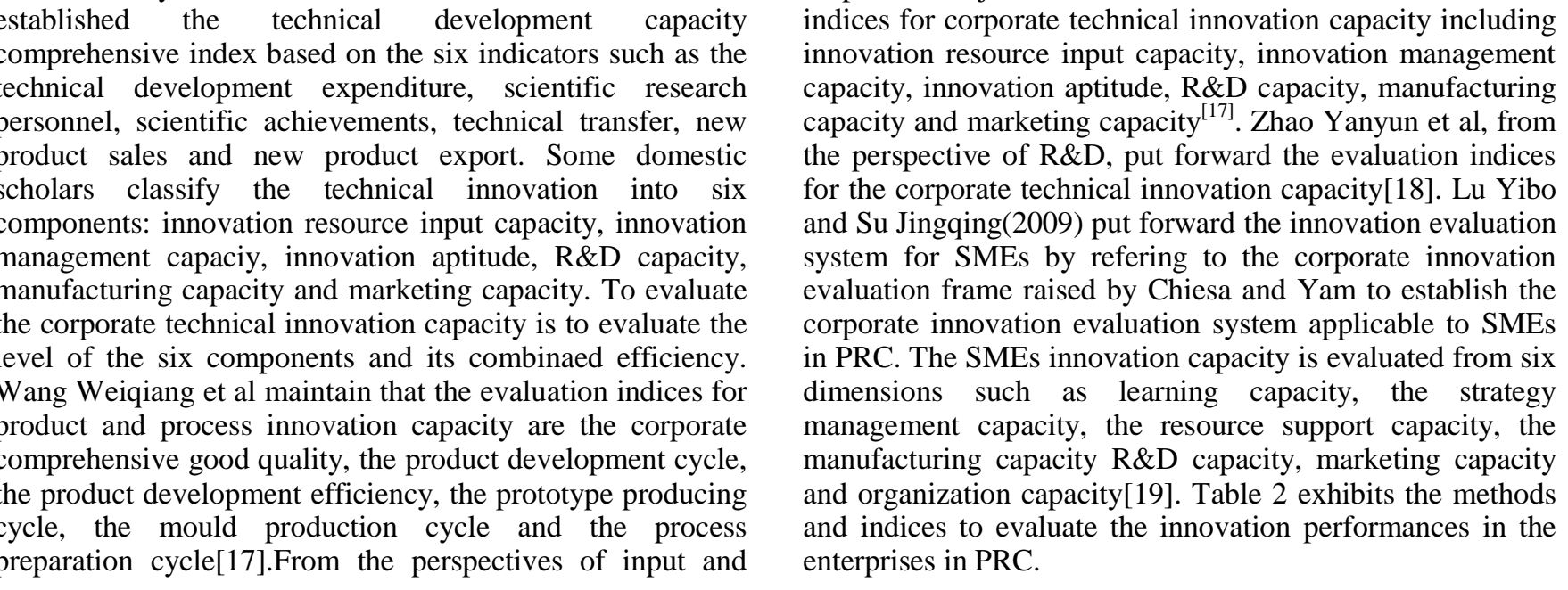

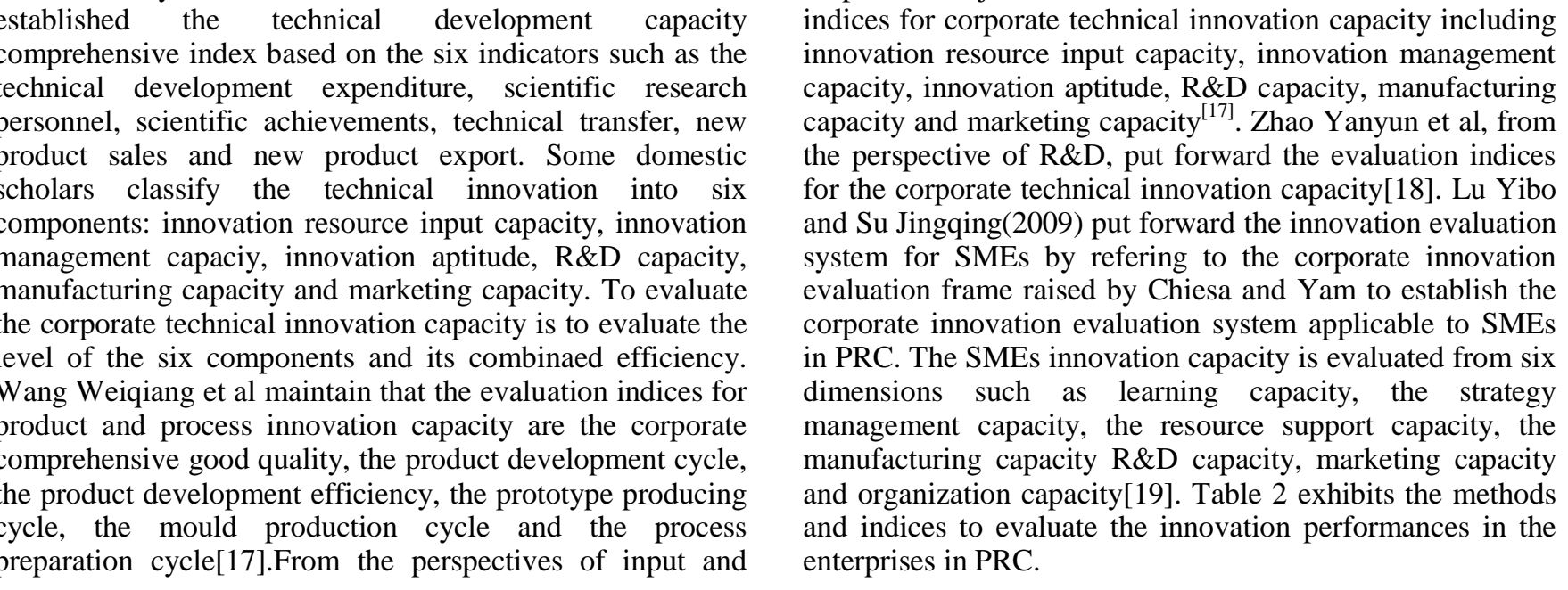

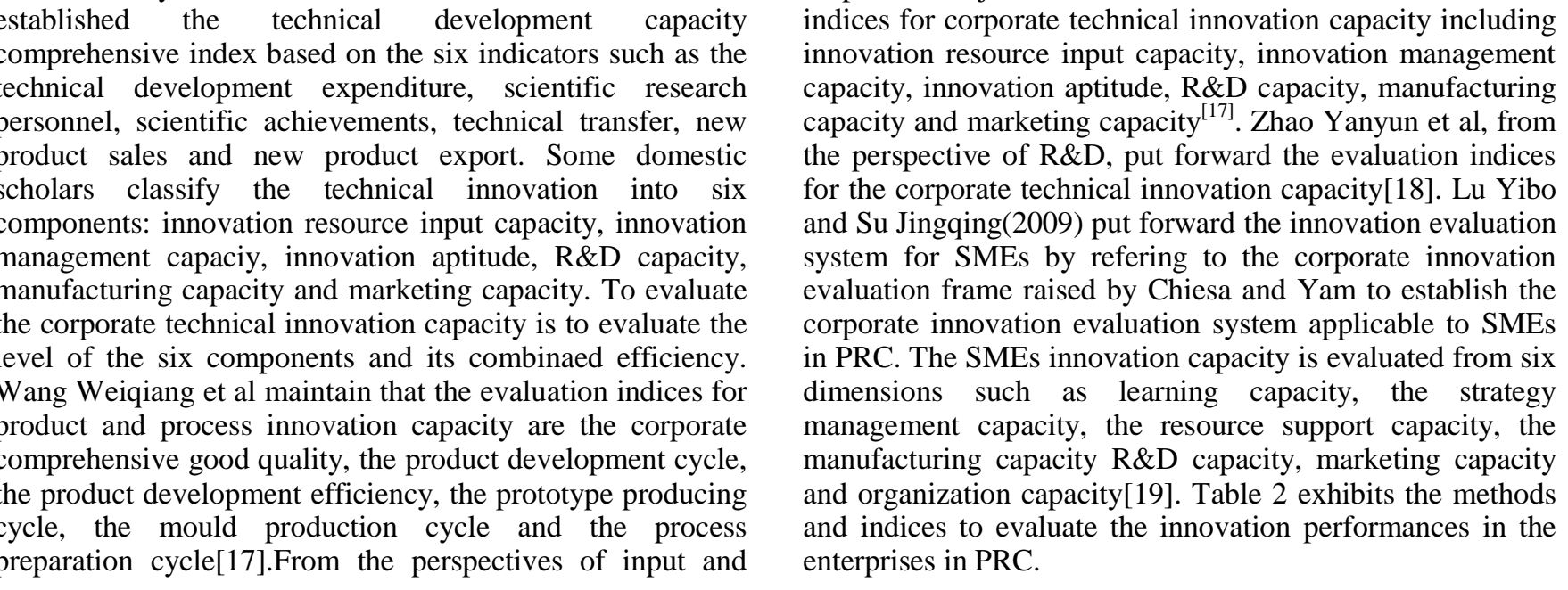

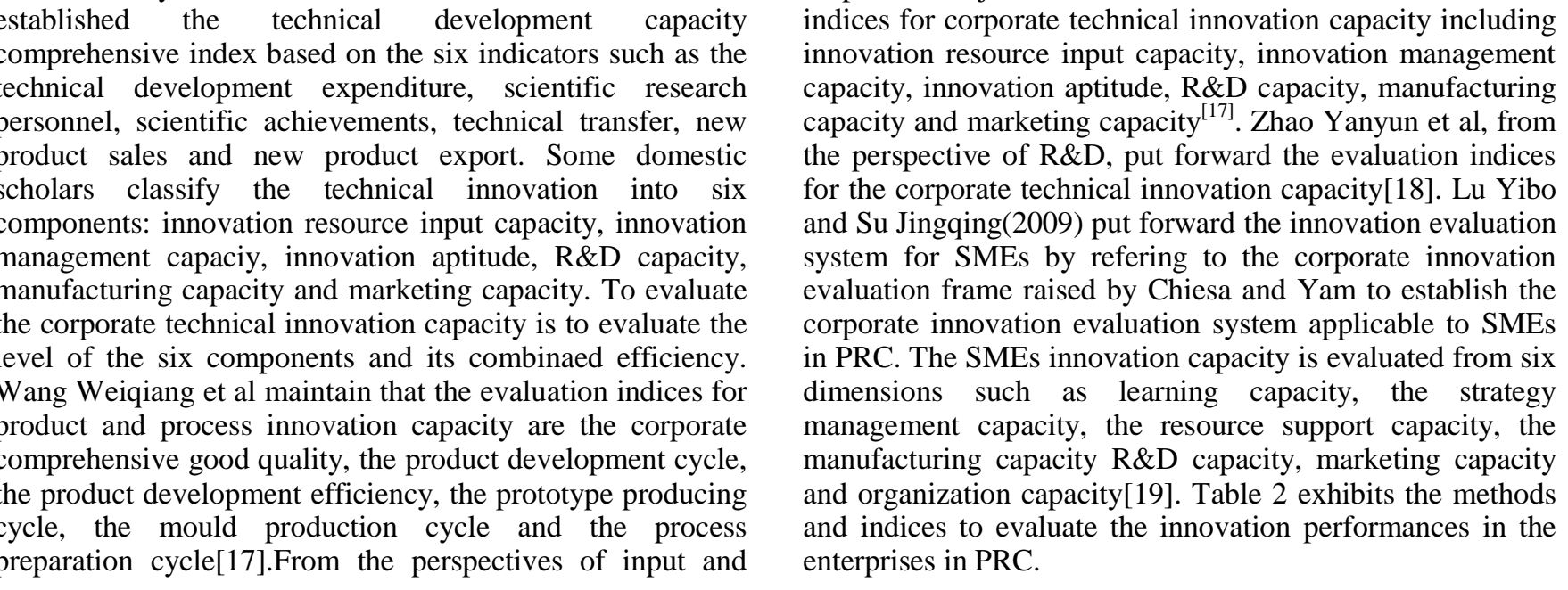

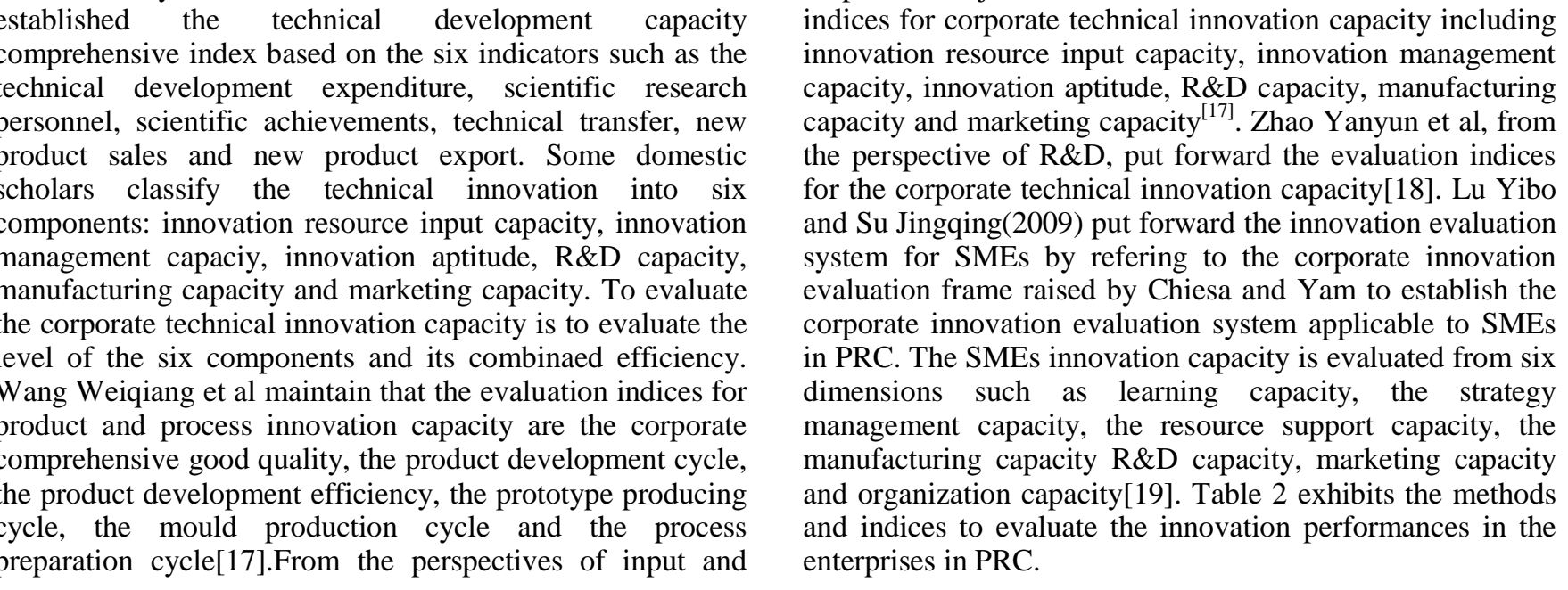

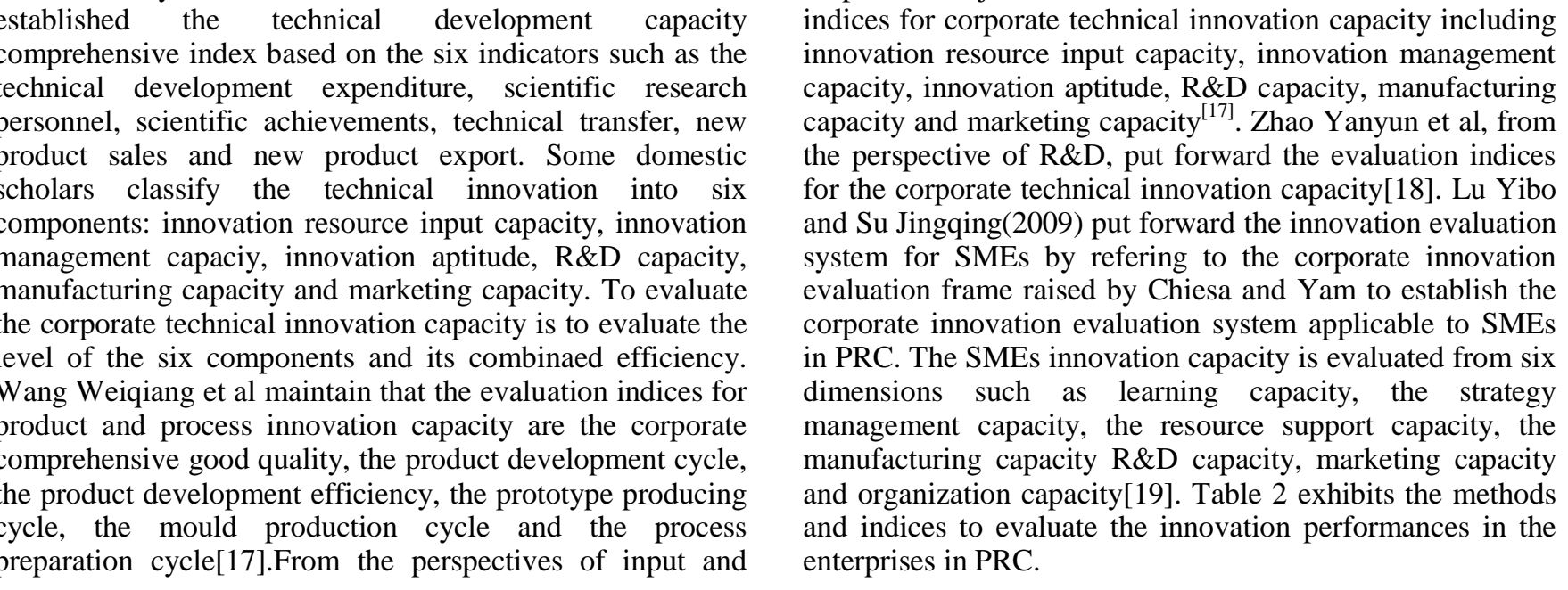

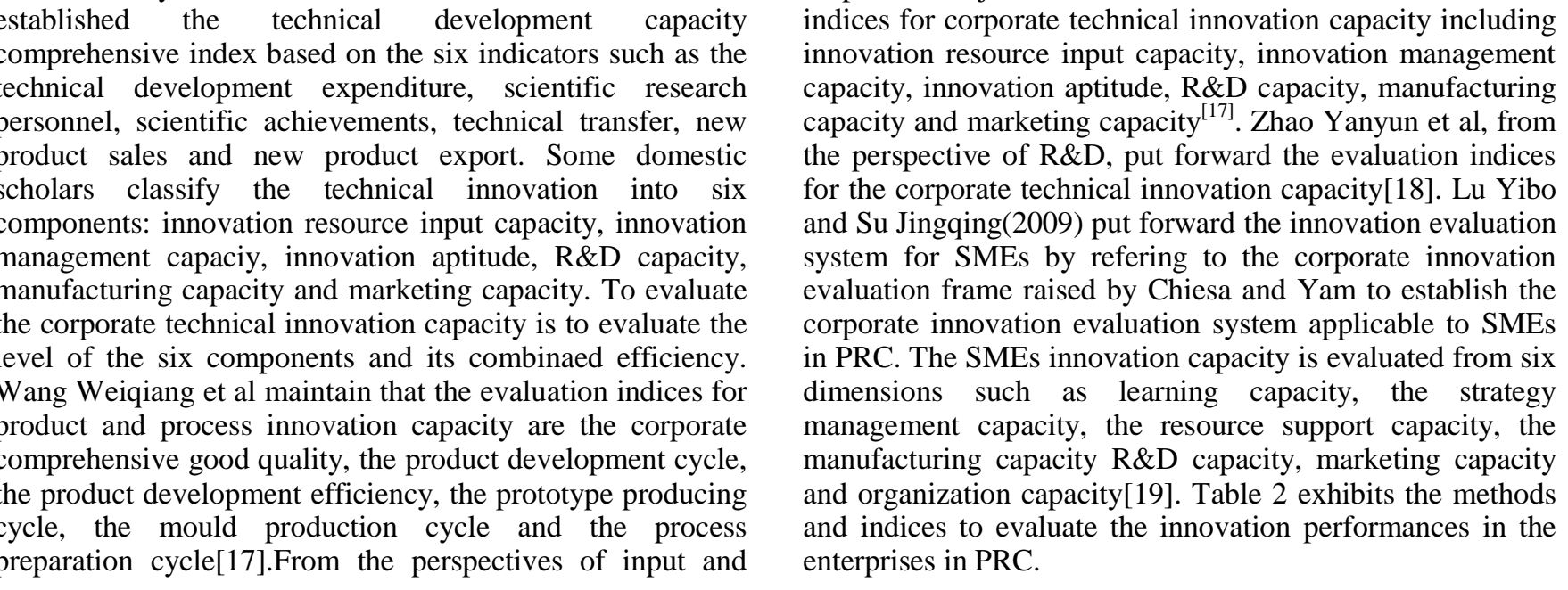

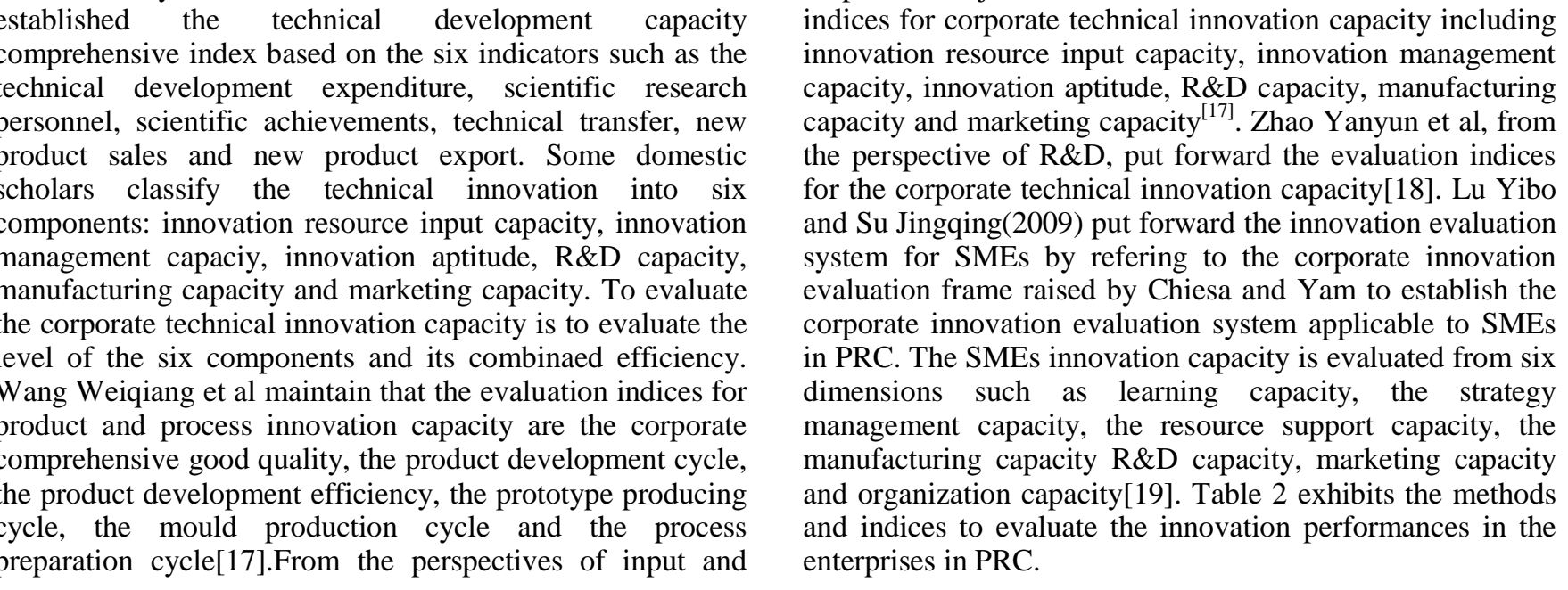

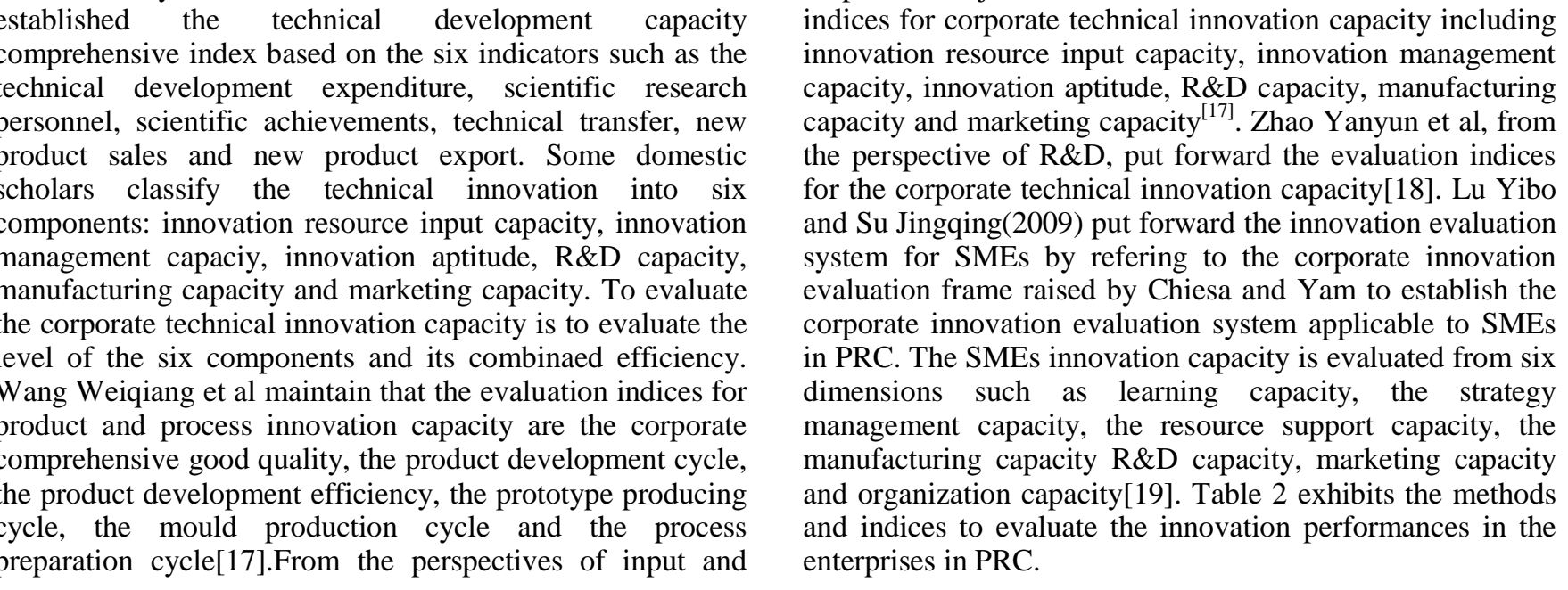

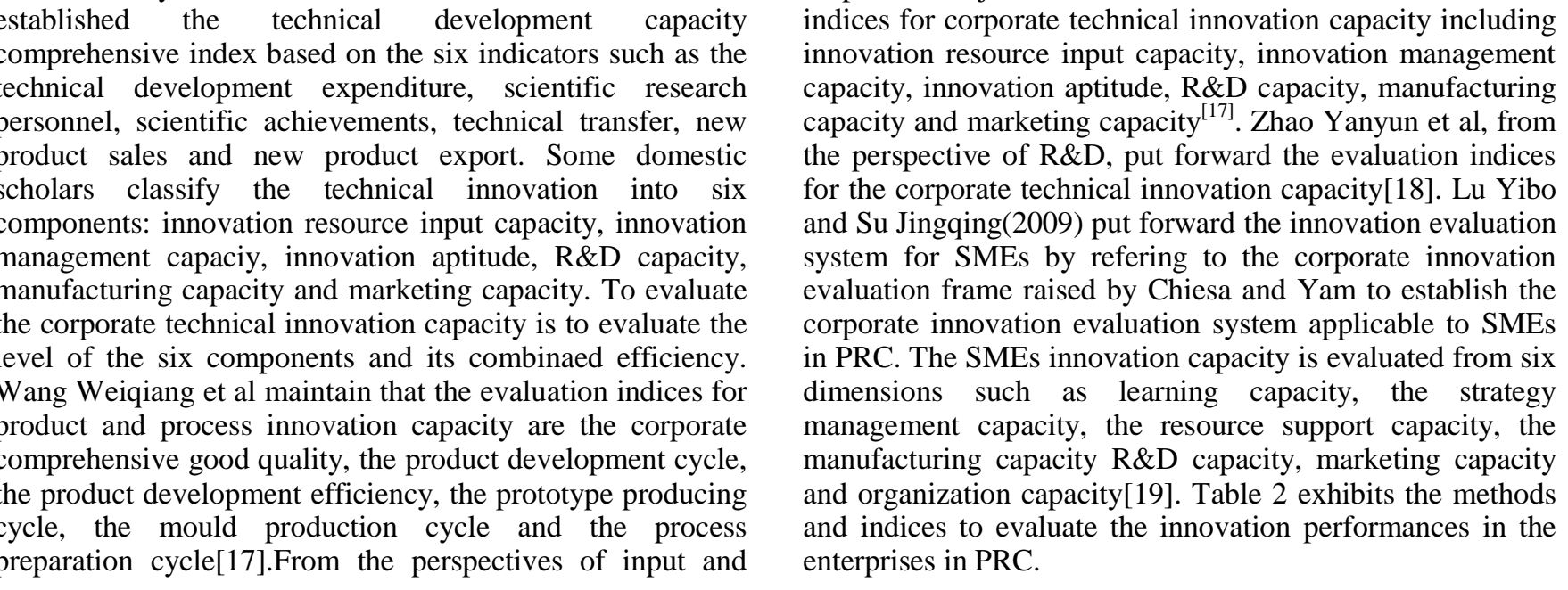

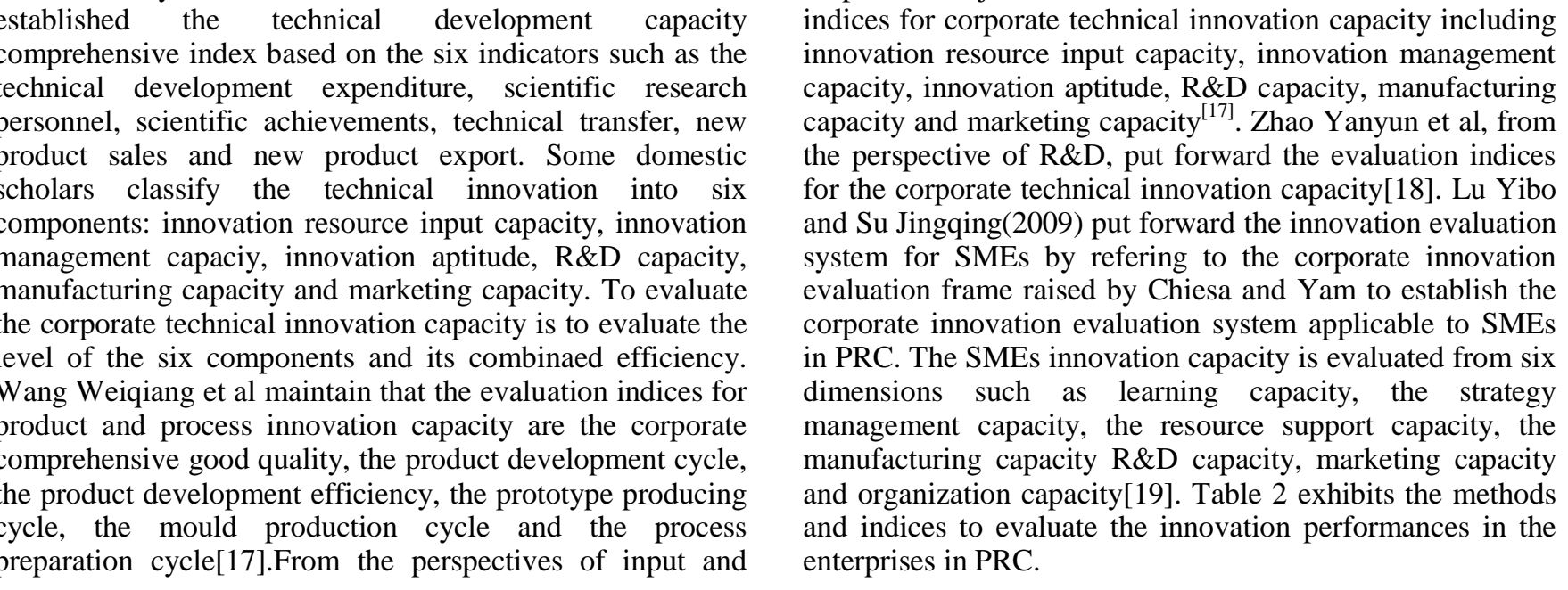

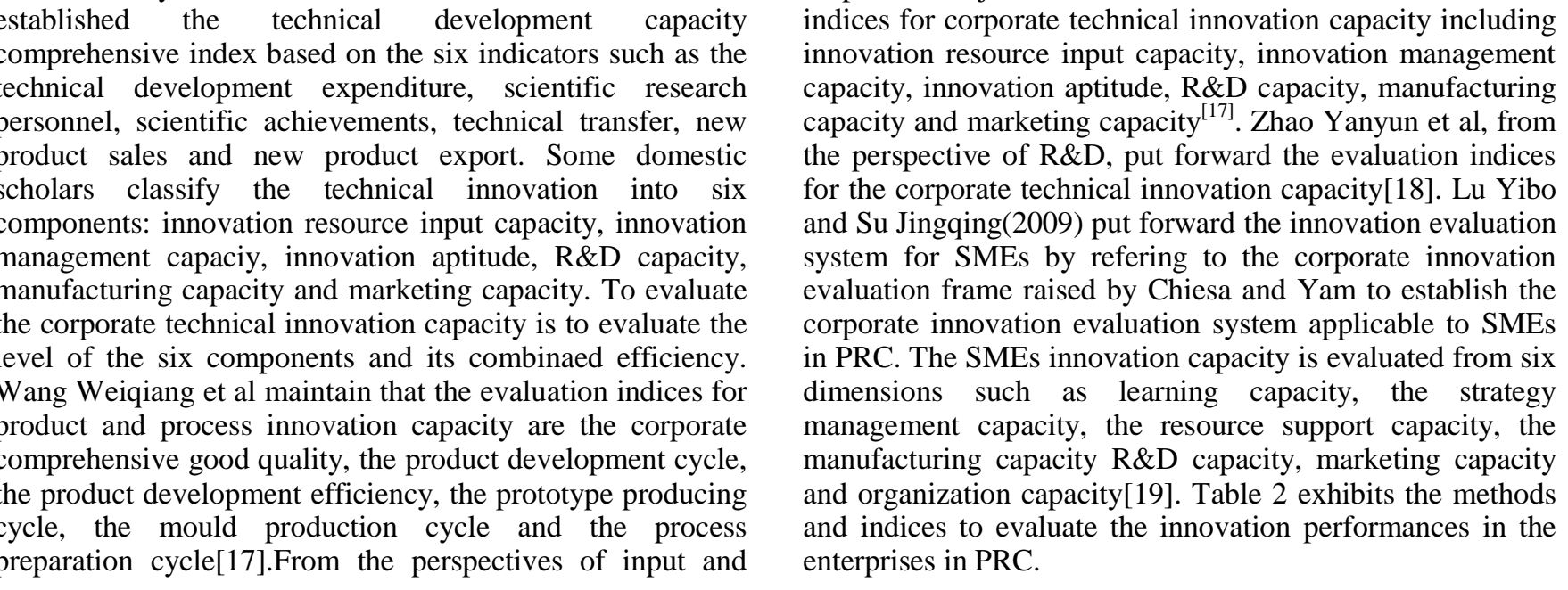

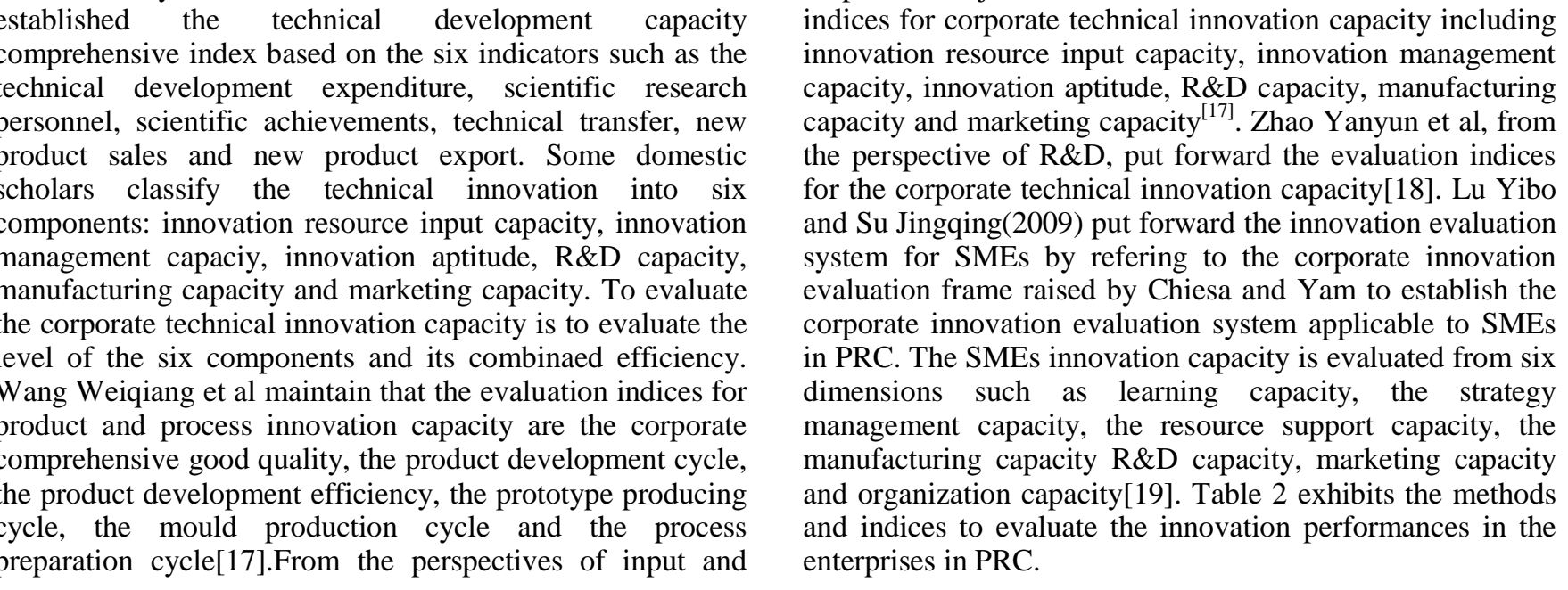

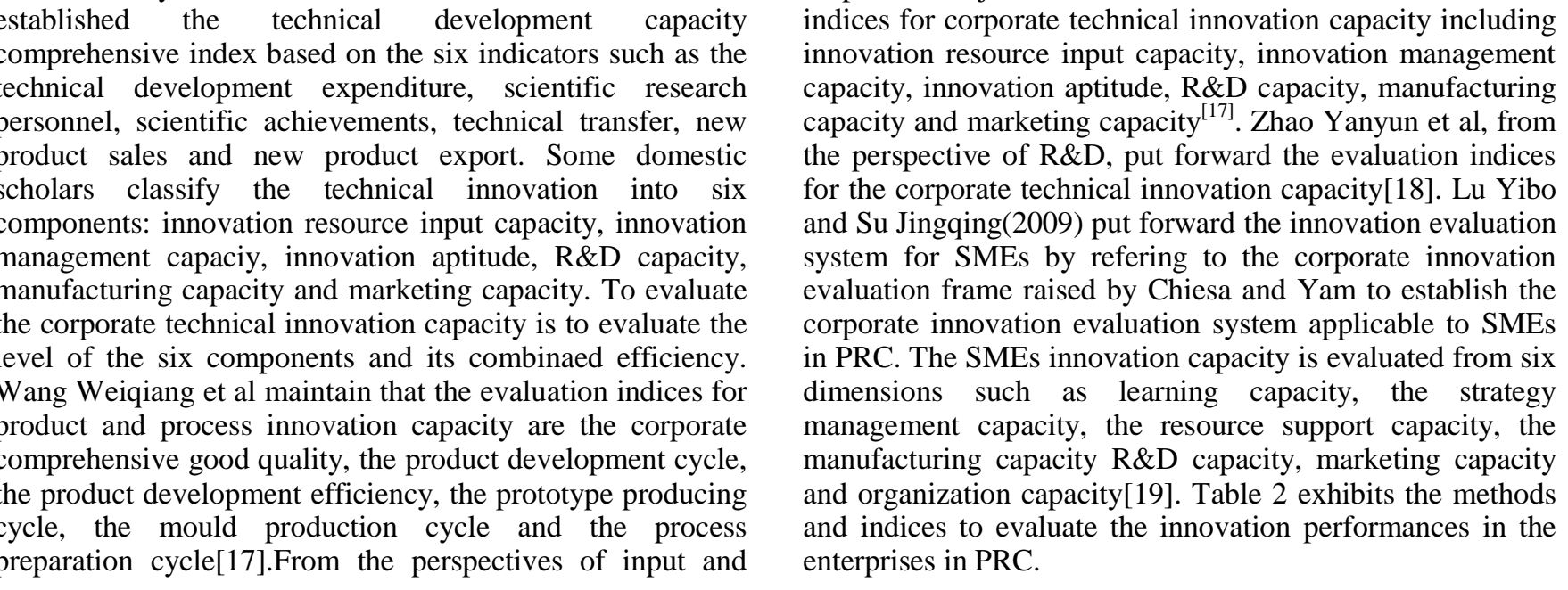

TABLE II. METHODS AND INDICES TO EVALUATE THE INNOVATION PERFORMANCES IN THE ENTERPRISES IN PRC

Major Viewpoints and Con
The corporate technical innovation performance evaluation in
social performance. Comprehensive judgement method in fuzz
comprehensively the corporate technical innovation performances.
The corporate innovation performance evaluation indices are
and innovation process performance, of which the innovation
performance, social performance, direct technical benefits and technic
From the perspective of acquiring resources, and with the help of
resource acquisition and the technical innovation is empirically proved.
Osculating value method is used to evaluate the corporate technical
The corporate technical innovation performance evaluation ind
social benefits and multi level gray evaluation method is used to evalu
DEA method is used to analyze the effect of the current situation
organization resource allocation in different regions of PRC on the in
"BSC(balanced scorecard" is used to put forward the four dimento
performances including technical innovation input, technical innovation
and financing condition.
Based on the impact of the social capital on the technical
multinominal regression and structural equation are used to make the
BSC is used to break the corporate technical innovation target
learning and growth, and then corresponding performance eval
requirements of each target.
On the basis of the above analysis, the author of this paper
eves that different evuation methods should be used to
uate corporate innovation of enterprises of various types
different. In addition, comparative analysis should be
on the corporate innovation home and abroad so as to
tify the lessons to be learned and to offer support to the
and vigorous innovation assit. This is what we lack of
the current research[20].

\section{ACKNOWLEDGMENT}

This work is supported by the China-Australia Cooperation Foundation of Shenzhen Polytechnic (Grant No. 1) and the project of Philosophy and Social Sciences for 12th Five-Year Plan of Shenzhen (Grant No. 125B051)

\section{REFERENCES}

[1] J.A. SchumPeter, The Theory of Economic Development. Commercial Press, 1997.

\section{Representative}

ent

are composed of economic gains and Scholars

Hu Enhua (2002), Shan Hongmei (2002)

Chen Jing et al. (2006) Zhang Fanghua (2006) Nie Ping et al. (2006) Wang Qingyun (2004) Gong Jiancheng et al.(2003)

Zhao Linan (2006)

\begin{tabular}{|c|} 
Zhao Linan (2006) \\
Wei Ying (2005) \\
\hline $\begin{array}{c}\text { Zhang Fanghua } \\
(2004), \text { Li Hong } \\
(2006)\end{array}$ \\
\hline
\end{tabular}

[2] Van de Ven, and Andrew, H., "Central problems in the management of innovation," Management Science 32, 1986.

[3] Wang Ning, "The Indices to Evaluate the Technical innovatio-oriented Enterprises and Empirical Research," Collection of Master Thesis of Jilin University,2006, unpublished.

[4] Ettlie J.E., Bridges,W.P., O' Keefe and R.D., “Organization strategy and structural differences for radical versus incremental innovation," Management Science 30, June, 1984, pp.682-695.

[5] Rupert Pennant-Rhea, and Clive Crook, Western Economic Evaluation. Beijing, China Forein and Trade Press, 1990.

[6] M. Mansfield, "Foreign Trade and US Research and Development," Review of Economic and Statistics, 1979. pp.2-5.

[7] $\mathrm{Xu}$ Qingrui, "Research on the Economic Control Mould with Corporate Technical Capaciy Applied to Innovation Benefits, " The Journal of Quantitative \& Technical Economics, 1997.

[8] Guan Shixu, Research on Technology and Innovation. China Social Sciences Publishing House, 2005.

[9] Fu Jiaji, Science of Technical Innovation. Tsinghua University Press, 1998.

[10] Jia Weiwen, "Technical innovation is the fundamental means to transfer the economic growth method in PRC," Science and Scientific Technical Management, 1997. 
[11] Liu Xie Lin, Technical Inovation Economics. China Economics Press, 1993.

[12] AnYana, "Technical Innovation-oriented Enterprise Innovation Evaluation Indices and Imprical Research,” Modern Management Science, 2011.

[13] Xu Qingrui, Chen Zhong, Basic Laws for Enterprise Operation Management and Patterns. Zhejiang University Press, 2001.

[14] Wei Jiang, Guo Bin, and Xu Qingrui, "Corporate Technical Capacity and Technical Innovation Capacity Evaluation Indices System," China Hi-tech Enterprices, 1995.

[15] Sun Wei, and Wang Huajun, "Research on Technical Innovation Capacity and Evalutation Indices," Heilongjiang Bayi Agricultural University Journal, 2002

[16] Song Xiaoli, and Liu Jianqiu, "Research on the Hi-tech Enterprises R\&D Capacity Generation and Evolutionary Biological Patterns," Enterprise Technical Development, 2009.
[17] Niu Yonghua, "Comprehensive Research on Technical Innovation Capacity Evaluation of Hi-tech Enterprises Listedin PRC, " Master Thesis, 2007, unpublished.

[18] Wei Jisnh, and Xu Wingrui, "Research on the Relation between Corporate Technical Capacity and the Technical Innovation Capacity," Scientific Research Management, 1996.

[19] Lu Yibo, and Su Jingqing, "Research on SMEs Innovation Capacity Based on the Innovation Capacity during the Innovation Process," Management Journal, 2009.

[20] Ma Shengiie, "The Enterprise's Ablity of Technology Innovations and its Evaluation Index System," Journal of Quantitive \& Technical Economics, 2002. 